\title{
Changing Probabilities of Days with Snow and Rain in the Atlantic Sector of the Arctic under the Current Warming Trend
}

\author{
E. B. ŁUPIKASZA \\ Faculty of Natural Sciences, Institute of Earth Sciences, University of Silesia in Katowice, Katowice, Poland \\ K. CIELECKA-NowAK \\ Faculty of Natural Sciences, Institute of Earth Sciences, University of Silesia in Katowice, Katowice, and Centre for Polar \\ Studies, Sosnowiec, Poland
}

(Manuscript received 29 May 2019, in final form 15 December 2019)

\begin{abstract}
Trends in the probabilities of days with liquid, solid, and mixed precipitation are discussed on annual and intra-annual scales along with their relationship to air temperature in the Atlantic sector of the Arctic. Data on weather phenomena were used to identify precipitation phases. The data cover various periods but all series extend to 2017. Trends in the annual air temperature and probability of precipitation phases for various long-term periods are discussed and differences in the mean air temperature and probability of precipitation phases between 1979-97 (insignificant warming) and 1999-2017 (significant warming) on an intra-annual scale. In the studied region, the precipitation phases were sensitive to warming and atmospheric circulation to various degrees, depending on the phase, mean climate, month, and local conditions. The probability of days with rainfall increased (by $+1 \%$ to $+3 \%$ per decade), whereas the probability of days with snowfall decreased (by $-1.5 \%$ to $-2.4 \%$ per decade). The increasing trends in the probability of rainy days at all stations and decreasing trends in the probability of snowy days in the southern part of the region were warming induced. The most significant and widespread trends in snowy and rainy days were found in September. The probability of days with mixed precipitation exhibited no trends due to an inverse reaction to warming in the warmer and colder parts of the year. Temporal variability in the probability of precipitation phases was significantly linked to three teleconnection patterns playing a role in various parts of the year.
\end{abstract}

\section{Introduction}

Precipitation, an important element of the water cycle, plays a significant role in the climate system, triggering numerous environmental processes (e.g., river runoff and discharge, flooding, landslides, transport of sediments, and glacier mass balance and dynamics) (Mackay 1987; Stieglitz et al. 2003; Grab 2005) and is decisive for life (Sturm et al. 2001; Putkonen and Roe 2003; Chapin et al. 2005). Moreover, precipitation is a driving element of the Arctic freshwater budget, which affects the Atlantic meridional overturning circulation and thus the global climate (Walsh et al. 1998; Kattsov and Walsh 2000; Førland and Hanssen-Bauer 2003a; Davies et al. 2014).

The frequency and type of precipitation are just as important as their quantity and intensity in understanding

\footnotetext{
Corresponding author: Łupikasza E. B., ewa.lupikasza@us. edu.pl
}

the seasonality of hydrological cycles and the health of the ecosystem in high-latitude regions (Ye 2008). The impact of precipitation on the environment depends on its phase. Liquid precipitation in the cold part of the year may lead to the build-up of ground ice on tundra, causing icing that reduces the availability of food for herbivores (Ims et al. 2008; Kausrud et al. 2008; Gilg et al. 2009; Hansen et al. 2011, 2014; Stien et al. 2012; Forbes et al. 2016) and affects inhabitants by reducing mobility (Hansen et al. 2014). Precipitation, depending on its phase, influences the thermal regime of frozen ground (Zhu et al. 2017). Solid precipitation plays a profound role in both the Arctic and global climate systems since it is crucial for the development of snow cover to be involved in a feedback mechanism that has significantly contributed to accelerated Arctic warming (Serreze et al. 2009; Screen and Simmonds 2010; Serreze and Barry 2011). In addition to clearly understood ice-albedo feedback (Groisman and Easterling 1994; Hu and Feng 2002; Perovich et al. 2007; 
Feng and Hu 2007; Screen and Simmonds 2012; Vihma et al. 2016), another snowfall-dependent feedback mechanism involves snow-covered ice. Screen and Simmonds (2012) have already demonstrated positive feedback associated with warming-induced reduction in summer snowfall in the Arctic. The loss of snow on ice results in a substantial decrease in surface albedo of a magnitude comparable to that caused by sea ice reduction.

The precipitation phase depends on the thermal structure of the troposphere between the ground and cloud base (Bocchieri 1980; Bourgouin 2000; Thériault et al. 2010), including air temperature inversions. In the Arctic, strong surface inversions appear in autumn and winter, while weaker elevated capping inversions dominate in spring and summer (Tjernström and Graversen 2009) and may modify the relationship between the ground air temperature and precipitation phase. Temporal changes in precipitation phases are also temperature dependent (e.g., Feng and Hu 2007; Førland and Hanssen-Bauer 2003a; Łupikasza 2008). Generally, higher temperatures lead to reduced snowfall and an increased rainfall fraction, but the rate and geographical distribution of these changes are nonlinear and depend on the ambient temperature and average climate conditions (Davis et al. 1999; Knowles et al. 2006; Ye 2008; Krasting et al. 2013; Bintanja 2018). In very cold conditions, temperature increases do not cause significant shifts in precipitation phases because, despite warming, temperatures remain well below the freezing point. At temperatures sufficiently elevated above $0^{\circ} \mathrm{C}$ with a small snowfall fraction, warming also leads to insignificant shifts in precipitation phases. The greatest warming-induced snowfall/rainfall changes occur in temperatures close to the freezing point (Knowles et al. 2006; Feng and Hu 2007; Bintanja 2018). Relationships between air temperatures and the frequency of precipitation phases may be reversed above or below particular threshold air temperatures (Ye 2008).

Although snowfall is not an early indicator of regional climate change due to its slower signal compared to air temperature (Krasting et al. 2013), many studies have used phase-based precipitation indices to monitor and detect responses to current climate change (Huntington et al. 2004; Dai 2008; Ke et al. 2009; Deng et al. 2017). Long-term changes in liquid-mixed-solid precipitation structures have already been reported in various regions. Snowfall or snowfall-to-precipitation $(S / P)$ ratios have decreased over some parts of North America (Karl et al. 1993; Groisman and Easterling 1994; Knowles et al. 2006; Huntington et al. 2004; Feng and $\mathrm{Hu}$ 2007) and across wide areas of eastern Europe and Asia (Ye 2008). In high-mountain regions such as the Tibetan Plateau (Ke et al. 2009; Wang et al. 2016; Deng et al. 2017; Zhu et al. 2017), the Tian Shan Mountains (Guo and Li 2015), and the Swiss Alps (Laternser and Schneebeli 2003), the direction of trends in snowfall and the snowfall-toprecipitation ratio have differed depending on the location, research period, and altitude. In central Europe, the $S / P$ ratio has been decreasing (Marty and Blanchet 2012; Serquet et al. 2011, Twardosz et al. 2012; Nikolova et al. 2013). A reduced ratio of solid to total precipitation was found between 1951 and 1995 in warm periods in the southern part of the Canadian Arctic, but no long-term trends were observed in the Canadian Arctic as a whole (Przybylak 2002). On the island of Spitsbergen, the annual fraction of solid precipitation declined, while mixed precipitation increased, between 1975 and 2001 (Førland and Hanssen-Bauer 2000, 2003a; Łupikasza 2008).

The reaction of precipitation phases to warming is complicated (Dai 2008; Bintanja 2018) and depends on the climatology of the air temperature itself and its rate of change; therefore, this aspect needs to be monitored, particularly in the rapidly warming Arctic (Serreze and Barry 2011; Andry et al. 2017). Although climate models project a reduction in total winter snowfall nearly throughout northern Europe, snowfall is projected to increase in the middle of the winter in the coldest areas of this region (Räisänen 2016). In the Arctic, the RCP8.5 scenario indicates a dramatic increase in rainfall due to the transformation of solid precipitation driven by changes in the air temperature of the lower troposphere, which govern whether the precipitation that starts off as snow will melt into rain on its way to the surface. Rain is projected to become the dominant form of Arctic precipitation by approximately 2080 (Bintanja 2018). The warming-induced trends in precipitation phases may be modified by other factors, such as atmospheric circulation, which impacts precipitation trends to a greater degree than temperature trends (Hanssen-Bauer and Førland 1998).

In this study, we discuss changes in the probabilities of liquid, mixed, and solid precipitation on annual, monthly, and submonthly scales using data from stations representing various climate conditions (mean annual air temperature from $-0.1^{\circ}$ to $-4.8^{\circ} \mathrm{C}$ ), which may alter the reaction of rain and snow to climate change. Previous studies on precipitation phases in the Atlantic sector of the Arctic focused on annual amounts of snow and rain for the period 1975-2001 (Førland and Hanssen-Bauer 2000, 2003a,b). We seek the answers to the following questions: 1) Are precipitation types in the Atlantic sector of the Arctic sensitive to accelerated warming of the Arctic, and if so, how? 2) Is geographical and intra-annual variability present in these reactions? Atmospheric circulation was suggested to influence the precipitation phase in the United States (Durkee et al. 2007; Feng and $\mathrm{Hu}$ 2007). Therefore, we also ask: How strong is the impact of atmospheric circulation on temporal variability in precipitation phases? To answer these questions, after 


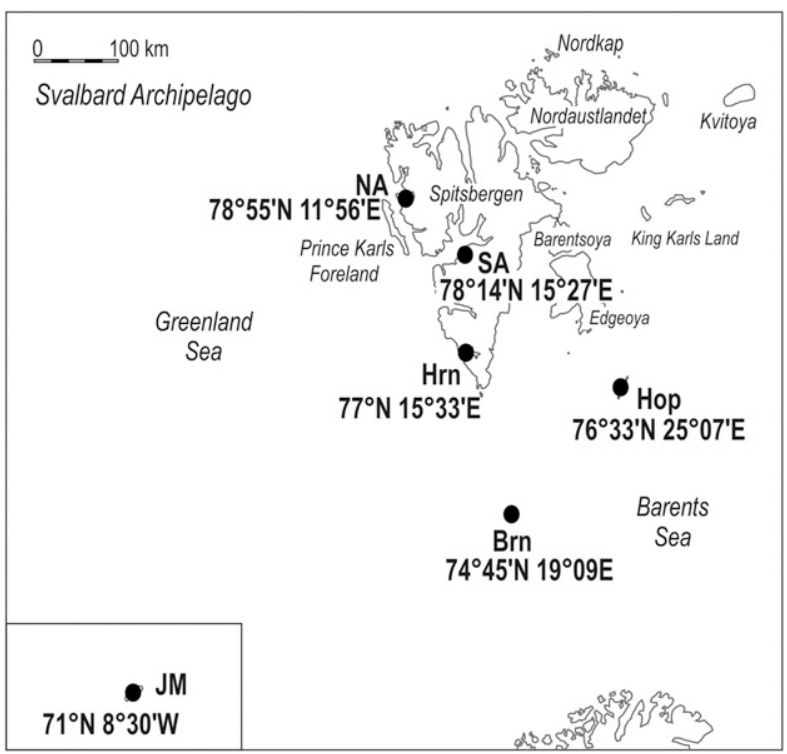

FIG. 1. Location of meteorological stations with their latitude and longitude: $\mathrm{NA}=\mathrm{Ny}$ Alesund [altitude (given in all cases as height above sea level): $8 \mathrm{~m}], \mathrm{SA}=$ Svalbard Airport $(28 \mathrm{~m}), \mathrm{Hrn}=$ Hornsund $(10 \mathrm{~m})$, Hop $=$ Hopen $(6 \mathrm{~m})$, Brn $=$ Bjornoya $(16 \mathrm{~m})$, and $\mathrm{JM}=$ Jan Mayen $(10 \mathrm{~m})$.

introducing our research (section 1) and describing our data and methods (section 2), we discuss the climatology of precipitation phases and air temperature within the study area (section 3); changes in annual and intra-annual air temperature (section 4) as a background for further analysis; and long-term changes in annual (section 5) and intra-annual (section 6) probabilities of particular precipitation phases. Section 7 attributes changes in liquid, mixed, and solid precipitation to changes in annual and daily air temperatures and annual and monthly circulation indices and is followed by a discussion (section 8) and conclusions (section 9).

\section{Data and methods}

This study is based on meteorological data for daily precipitation totals, information on the precipitation type, and daily air temperatures for "precipitation days" running from 0600 UTC of one day to 0600 UTC of the previous (in accordance with official standards applied in most of the European national weather services). Daily meteorological data were obtained from the Norwegian Meteorological Institute (eKlima). Data in the eKlima dataset undergo quality checks and are therefore marked with quality flags. We used data flagged with the highest quality codes, OK and LU. The OK level means one of the three following options: 1) a value was controlled and found correct, 2) a value was controlled and corrected, or 3) a value was missing and interpolated. The LU level indicates uncontrolled values that are thus somewhat uncertain (see http://eklima.met.no for detailed information). We controlled the quality of the LU flagged data by comparison with the data derived from other databases. The eKlima dataset was our primary data source due to the completeness and length of the time series it contains. To fill gaps and for purposes of quality control of the uncontrolled eKlima data, we used synoptic data of subdaily resolution (every $3 \mathrm{~h}$ between 0000 and 2100 UTC) derived from the OGIMET database (www.ogimet.com) in the form of SYNOP messages covering the period from October 1999 to the present. In the case of OGIMET data, precipitation phases were identified based on notations of weather phenomena coded as current (ww) and past (W1) weather. Inconsistencies between the two databases were rare, mostly concerning trace precipitation that was excluded from the analysis. The eKlima data for Hornsund were also compared to data supplied by the Institute of Geophysics, Polish Academy of Sciences. Finally, we collected chronological series for six meteorological stations located in the Atlantic sector of the Arctic (Fig. 1). All stations work within the WMO synoptic network and operate in accordance with WMO standards. At Hopen Station, a relocation of the rain gauge in 1997 led to a break in the homogeneity of precipitation totals; however, no inhomogeneity was reported in precipitation occurrence (Hanssen-Bauer et al. 2019). These meteorological stations represent a latitudinal belt $7^{\circ}$ wide $\left(71^{\circ}-\right.$ $78^{\circ} \mathrm{N}$ ) with a prominent air temperature gradient and various rates of warming (see section 4), which may have caused spatial variability in the occurrence and trends of liquid, mixed, and solid precipitation. The length of the time series depends on the availability of the data on the precipitation phase and differs depending on the individual station. The longest chronological series, covering the period 1956-2017, were collected for Jan Mayen (JM), Bjornoya (Brn), and Hopen (Hop). The series from meteorological stations located on Spitsbergen cover 19692017 for Ny-Alesund (NA), 1976-2017 for Svalbard Airport (SA), and 1979-2017 for Hornsund (Hrn).

The basic entity used in this study was a day with liquid, mixed, or solid precipitation. A day with sleet or snow and rain occurring at various times (not simultaneously) was classified as a day with mixed precipitation. Hence, a day with mixed precipitation should not be interpreted as a day with sleet. The average numbers of days with snow and rain and days with sleet, both constituting days with mixed precipitation, based on the available data from OGIMET for the period 2000-17, are presented in Table 1 . Trace precipitation $(<0.1 \mathrm{~mm})$ was excluded from the analyses due to its minor significance in environmental processes.

Precipitation data are burdened with serious measurement errors, particularly in the Arctic, where the combination 
TABLE 1. Average number of days with snow and rain (SR) and days with sleet (SI) in the period 2000-17. The calculation was performed based on available 3-h data from the OGIMET database between 2000 and 2017; NA = Ny Alesund, SA = Svalbard Airport, Hrn $=$ Hornsund, Hop $=$ Hopen, Brn $=$ Bjornoya, and JM $=$ Jan Mayen.

\begin{tabular}{|c|c|c|c|c|c|c|c|c|c|c|c|c|c|}
\hline & & Jan & Feb & Mar & Apr & May & Jun & Jul & Aug & Sep & Oct & Nov & Dec \\
\hline \multirow[t]{2}{*}{ NA } & SR & 0.7 & 0.4 & 0.2 & 0.3 & 0.4 & 0.4 & 0.1 & 0.4 & 1.2 & 0.7 & 0.6 & 0.1 \\
\hline & Sl & 1.6 & 0.9 & 0.9 & 1.1 & 1.9 & 0.8 & 0.4 & 0.9 & 1.7 & 2.5 & 1.6 & 1.1 \\
\hline \multirow[t]{2}{*}{ SL } & SR & 0.1 & 0.1 & 0.0 & 0.2 & 0.2 & 0.1 & 0.0 & 0.2 & 0.3 & 0.8 & 0.3 & 0.2 \\
\hline & $\mathrm{Sl}$ & 2.1 & 1.5 & 1.3 & 1.3 & 2.4 & 2.3 & 0.6 & 0.9 & 2.5 & 3.1 & 2.6 & 1.9 \\
\hline \multirow[t]{2}{*}{ Hrn } & SR & 0.8 & 0.9 & 0.7 & 0.5 & 0.4 & 0.4 & 0.3 & 0.3 & 1.1 & 1.6 & 1.4 & 0.7 \\
\hline & Sl & 3.2 & 2.1 & 1.9 & 1.9 & 3.4 & 2.4 & 0.8 & 0.8 & 3.0 & 3.4 & 4.0 & 3.3 \\
\hline \multirow[t]{2}{*}{ Hop } & SR & 0.3 & 0.4 & 0.4 & 0.8 & 0.6 & 0.7 & 0.4 & 0.5 & 0.6 & 1.4 & 1.3 & 0.7 \\
\hline & $\mathrm{Sl}$ & 1.8 & 2.1 & 2.2 & 2.1 & 3.4 & 2.4 & 1.2 & 0.8 & 2.9 & 4.1 & 3.4 & 2.7 \\
\hline \multirow[t]{2}{*}{ Brn } & SR & 1.5 & 1.6 & 1.5 & 1.1 & 1.4 & 0.9 & 0.1 & 0 & 1.0 & 1.9 & 2.1 & 1.8 \\
\hline & $\mathrm{Sl}$ & 3.2 & 2.8 & 3.6 & 3.7 & 3.8 & 2.0 & 0.4 & 0.3 & 1.9 & 3.0 & 3.6 & 4.2 \\
\hline \multirow[t]{2}{*}{ JM } & SR & 2.3 & 2.0 & 2.7 & 2.4 & 1.7 & 1.6 & 0 & 0.1 & 1.3 & 1.9 & 2.7 & 2.5 \\
\hline & $\mathrm{Sl}$ & 4.3 & 4.0 & 2.8 & 2.6 & 2.2 & 1.2 & 0.1 & 0.1 & 1.6 & 3.7 & 4.8 & 3.8 \\
\hline
\end{tabular}

of dry snow, high wind speed, and open tundra dramatically exacerbates errors (Førland and HanssenBauer 2003b). The "undercatch" error may exceed 50\% near the poles in winter (Legates and Willmott 1990; Groisman et al. 1991; Sevruk 1993; Groisman and Legates 1994; Dai et al. 1997; Rasmussen et al. 2012). Quality control of precipitation data, particularly in polar regions, is challenging due to the limited number of stations (Hanssen-Bauer et al. 2019). Hence, the acquisition of reliable estimates of trends in precipitation totals, particularly snowfall, is a challenge (Yang et al. 2005; Groisman et al. 2015; AMAP 2017; Hanssen-Bauer et al. 2019). In this study, therefore, we focus on changes in the probability of precipitation phases rather than on totals on annual, monthly, and submonthly scales. Probability was calculated as the quotient of the number of days with a particular precipitation phase (events that occurred, NDXP) and the number of all days within a particular time scale (number of potential/possible events in a year, month, or submonthly period, NDp, which is equal to the number of days in that period) and expressed as a percentage [Eq. (1)]:

$$
\mathrm{XPP}=\frac{\mathrm{NDXP}}{\mathrm{NDp}} \times 100[\%],
$$

where XPP is the probability of precipitation phases in which $X$ may be $L$ (liquid), $M$ (mixed), or $S$ (solid); NDXP is the number of events that occurred, meaning the number of days with a particular precipitation phase; and NDp is the number of possible cases determined by the number of days in a year (365 or 366), month $(28,29$, 30 , or 31$)$, or submonthly period $(9,10$, or for February 8 or 9$)$.

This index is insensitive to the varying duration of months, submonthly periods, or gaps in the data. To analyze changes in the submonthly probability of days with liquid, solid, and mixed precipitation, we divided each month into three periods, two of which were 10 days long, whereas the third depended on the duration of the given month and thus covered between 8 and 11 days. These submonthly periods are called "decads" in the remainder of this paper. To identify general changes in the annual probability of precipitation phases, we calculated nonparametric trends (Sen's slope) for the entire chronological series of various lengths depending on the station and for the period 1979-2017, which is common to all stations. Trends were also calculated for 30-yr (19882017), 25-yr (1993-2017), and 20-yr (1998-2017) periods, all ending in 2017 , enabling us to check the temporal evolution of the directions and rates of these trends. The nonparametric Mann-Kendall test (Mann 1945; Sen 1968; Kendall 1975; Hamed and Rao 1998) was used to assess trend significance, with $\alpha \leq 0.05$ used as a threshold for significant trends. Precipitation trends, due to great inherent variability in the precipitation time series, must be strong to be statistically significant (Førland and HanssenBauer 2003a). Therefore, we also paid attention to weak trends that were statistically significant at $\alpha<0.1$. Changes in decadal and monthly probabilities of liquid, mixed, and solid precipitation were assessed based on their differences between the 19-yr periods of 1979-97 and 1999-2017. Differences in mean monthly probabilities were tested with respect to statistical significance using the MannWhitney test (Wilcoxon 1945; Cheung and Klotz 1997). For this purpose, we first calculated the monthly probability for each year, followed by mean monthly probabilities for the 19-yr research periods, and then checked the significance of the differences in means between these periods. Since a precipitation phase depends on the air temperature, we also calculated trends and differences in the mean air temperature for the same long-term periods as for the precipitation phases (mentioned above). Changes in the precipitation phases were attributed to the air temperature by calculating 1) Spearman correlation 
coefficients between the series of annual probabilities of particular precipitation phases and air temperatures and 2) differences in the frequency of each precipitation phase at daily air temperature intervals of $2^{\circ} \mathrm{C}$ between 1979-97 and 1999-2017. Daily mean temperature does not necessarily represent the temperature during the part of the day when precipitation was falling therefore systematic biases may influence some of the findings. Additionally, we calculated the frequencies of daily air temperatures for the intervals and differences in these frequencies between these two 19-yr periods. Correlations were also calculated for detrended series in order to assess the pure relationship of precipitation phase and air temperature and the effect of warming on precipitation trends. The detrending was performed using second-degree polynomial regression (Shumway and Stoffer 2017).

To address the impact of atmospheric circulation on days with particular precipitation phases, we also calculated Spearman correlations between detrended series of annual and monthly probabilities of precipitation phases and six circulation indices. The calculations were performed for the common period of 1979-2017. The indices reflect the prominent teleconnection patterns over the North Atlantic or Eurasia: North Atlantic Oscillation (NAO), east Atlantic pattern (EA), east Atlantic/western Russia pattern (EATL/WRUS), Scandinavia pattern (SCAND), and polar/Eurasia pattern (PE). Time series of circulation indices were derived from the Climate Prediction Center/National Oceanic and Atmospheric Administration (CPC/NOAA) data. The CPC/NOAA indices are based on RPCA (rotated principal component analysis) technique applied to monthly mean standardized 500-mb height anomalies (https://www.cpc.ncep.noaa.gov/ data/teledoc/telecontents.shtml).

The teleconnections reflect coupling between the upper air quasi-stationary, planetary-scale circulation and short-term climatic fluctuations near the surface (Seierstad et al. 2007) and were recognized to influence air temperature and precipitation regimes and the location and intensity of the major jet streams and associated storm track over vast areas (Panagiotopoulos et al. 2002). Therefore, these teleconnections may also drive the occurrence of snow and rain. In this study, we present the results for three circulation indices (NAO, SCAND, and PE) that had a significant impact on the probability of days with precipitation phases in the Atlantic sector of the Arctic. The CPC/NOAA NAO index is defined as a north-south dipole of anomalies, with one center located over southern Greenland and the other center of opposite sign spanning the central latitudes of the North Atlantic between $35^{\circ}$ and $40^{\circ} \mathrm{N}$. The Scandinavian pattern in its positive phase consists of a primary circulation center over Scandinavia, with weaker centers of opposite signs over western Europe and eastern Russia/western Mongolia. The positive phase of the polar Eurasian pattern includes negative height anomalies over the polar region and positive anomalies over northern China and Mongolia reflecting an enhanced circumpolar vortex. A detailed description of the teleconnection patterns and methods used for their identification is discussed in, among others, Barnston and Livezey (1987) and Panagiotopoulos et al. (2002).

\section{Climatology of liquid, mixed, and solid precipitation against the background of air temperature}

In this section, as a foundation for further analysis, we discuss the annual and decadal probability of each precipitation phase against the background of air temperature climatology (Fig. 2). On an annual scale, solid precipitation (SP) dominated other phases. Days with liquid precipitation (LP) were more numerous than those with mixed precipitation (MP) at each station. The annual number of days with precipitation phases varied depending on the geographical location and was driven by latitudinal variations in air temperature.

The annual probability of days with both liquid (LPP) and mixed (MPP) precipitation increased from $10 \%$ (LPP) and 6\% (MPP) at NA, located farthest to the north, to $25 \%$ (LPP) and 17\% (MPP) at JM, located almost $1000 \mathrm{~km}$ from Svalbard to the southwest. The distribution of solid precipitation probabilities (SPPs) was more complicated. Its highest values (37\%) at Hop located on the Barents Sea resulted from a combination of relatively low air temperature due to the proximity to sea ice during large parts of the year, the influence of the cold Sørkapp Current, and the greater availability of moisture (brought by midlatitude cyclones affecting the island; Jakobson and Vihma 2010) compared to the stations located to the north. The minimum probability of days with snowfall at NA $(24 \%)$ is explained by availability of moisture in the air (which, besides air lift, is necessary to ice crystals growth and increases the possibility of precipitation occurrence) less than that at Hopen in conjunction with similarly low air temperatures (Figs. 2a,d).

The intra-annual structure of precipitation phases exhibited both shared and individual features. The high season of snowfall probability, denoting high values with no clear increase or decrease, started earliest at NA (second decad of October) and latest at JM (at the turn of November and December) but lasted at all stations until the third decad of March, coinciding with an increase in air temperature due to increasing solar elevation in the Northern Hemisphere. In the snowiest decads 

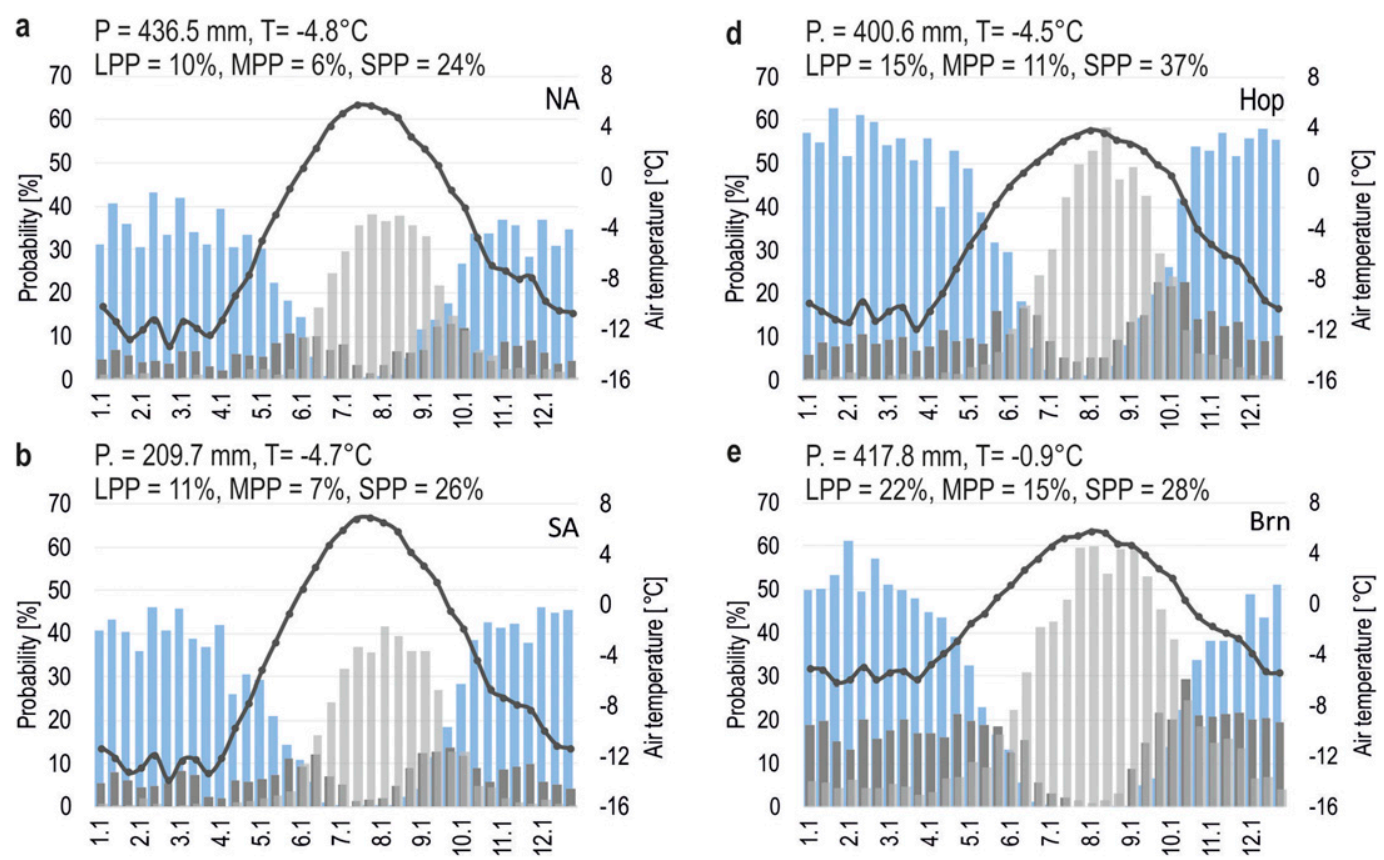

e $\quad P .=417.8 \mathrm{~mm}, \mathrm{~T}=-0.9^{\circ} \mathrm{C}$
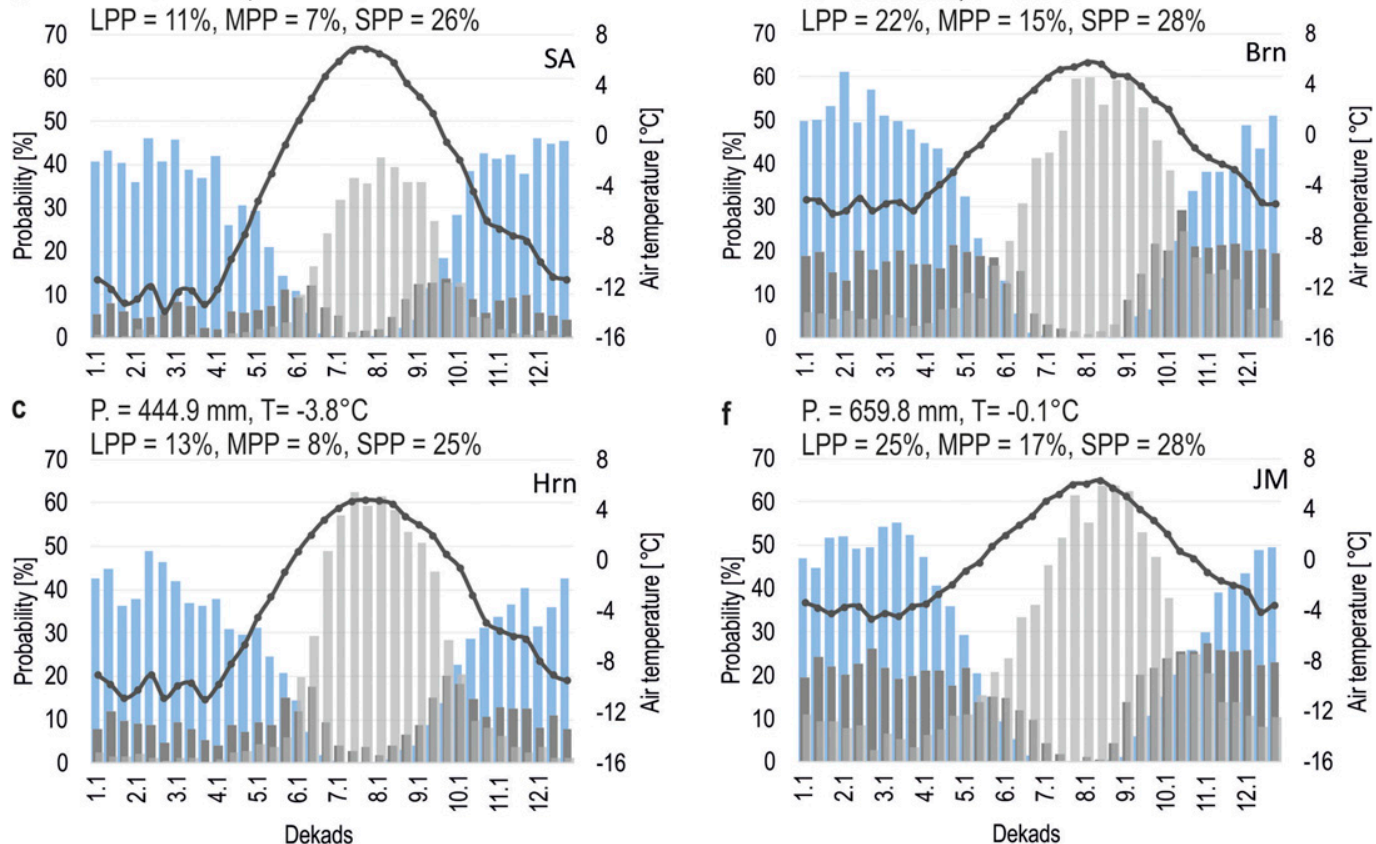

FIG. 2. Annual course of decad probability of solid (blue bars), mixed (dark gray bars), and liquid (light gray bars) precipitation and average air temperature (black line) in the Atlantic sector of the Arctic for 1979-2017; $P=$ annual precipitation total, $T=$ annual air temperature, LPP $=$ annual probability of liquid precipitation, $\mathrm{MPP}=$ annual probability of mixed precipitation, $\mathrm{SPP}=$ annual probability of solid precipitation.

of this season, SPPs varied between a maximum of $60 \%$ (Hop) and a minimum of $30 \%$ (NA). Decads free of snowfall were rare, occurring at NA, Hrn, and JM (in July); only in Brn were there three such decads at the turn of July and August (Fig. 2).

The shape of the decadal probability of days with liquid precipitation was unimodal, with high values populating approximately five decads, usually between the first decads of July and September. The maximum decad probability of rainfall exceeded $60 \%$ at JM and reached its minimum of $35 \%$ at NA and SA (Fig. 2). Rainless decads were recorded only at NA and SA at the turn of March and April. The highest decad LPP clearly exceeded the SPPs at Hrn and JM (Figs. 2c,f).

Two patterns of decad MPP were identified. One, a bimodal pattern with two maximums in June and at the turn of September and October, with probability between $10 \%$ and $20 \%$, was characteristic of stations located on Spitsbergen (NA, SA, Hrn) and at Hop. The other pattern, identified at stations located at lower latitudes, consisted of one summer minimum in August, whereas in the other decads the MPP was almost uniform, reaching approximately $20 \%$ (Brn and JM) (Figs. 2e,f). A nearly equal probability of all precipitation phases was noted in decads with average air temperatures close to $0^{\circ} \mathrm{C}$ : in spring between the second decad of June (Hop) and the second decad of May (JM), and in autumn between the third decad of September (NA and SA) and the third decad of October (JM), depending on station. In both autumn and spring, a shift of four decads occurred in the decad marking the first occurrence of the freezing point within the research area. 


\section{Changes in average annual and decad air temperature}

The climatology of air temperature on Svalbard has been presented in several studies (e.g., Førland et al. 2011; Nordli et al. 2014; Gjelten et al. 2016). In this section, we focus on changes in annual and submonthly (decad) air temperatures. Presented in Fig. 3 is the spatial distribution of annual air temperature (AAT) based on data from NCEP-NCAR reanalysis in the two periods (1979-97 and 1999-2017) used in this study to find changes in the probability of precipitation phases and differences in AAT between these periods. The meteorological stations used in this study are located in an area characterized by large air temperature gradients (Figs. 3a,b) and rapid warming (Fig. 3c). The range of AAT over Spitsbergen varied from less than $-4^{\circ} \mathrm{C}$ to less than $-10^{\circ} \mathrm{C}$ in the period $1979-97$ and from less than $-2^{\circ} \mathrm{C}$ to close to $-8^{\circ} \mathrm{C}$ in the period $1999-2017$, which indicates warming at a rate of more than $2 \mathrm{~K}$ over 40 years at NA, SL, Hrn, and Hop. The eastern part of Spitsbergen and the smaller islands of the Svalbard
Archipelago located east of Spitsbergen have been subject to warming at a rate of more than $3^{\circ} \mathrm{C}$ over the same 40-yr period. Unfortunately, no meteorological station operates in that part of the island; however, according to Hanssen-Bauer et al. (2019), the eastern part of the Svalbard Archipelago is colder than the western and southern parts. At lower latitudes (Brn and JM), the rate of warming was close to $1^{\circ} \mathrm{C}$. Variations and gradients of AAT within the research area, as shown in the previous section, influence the spatial distribution of liquid, mixed, and solid precipitation. Warming may lead to significant long-term changes in the structure of precipitation with respect to phase.

Despite various warming rates, the pattern of the long-term course of AAT was similar at all stations. The correlation coefficients for AAT between stations for the period 1979-2017 varied from 0.817 to $0.984(\alpha<$ 0.0001). The longest of the AAT series (Hop, Brn, JM) indicated predominant variability and short-term tendencies between 1956 and 1980, with minimums in 1968 $\left(-10.6^{\circ},-5.4^{\circ}\right.$, and $\left.-4.1^{\circ} \mathrm{C}\right)$. Gradual and continuous warming started at the beginning of the 1980s and lasted

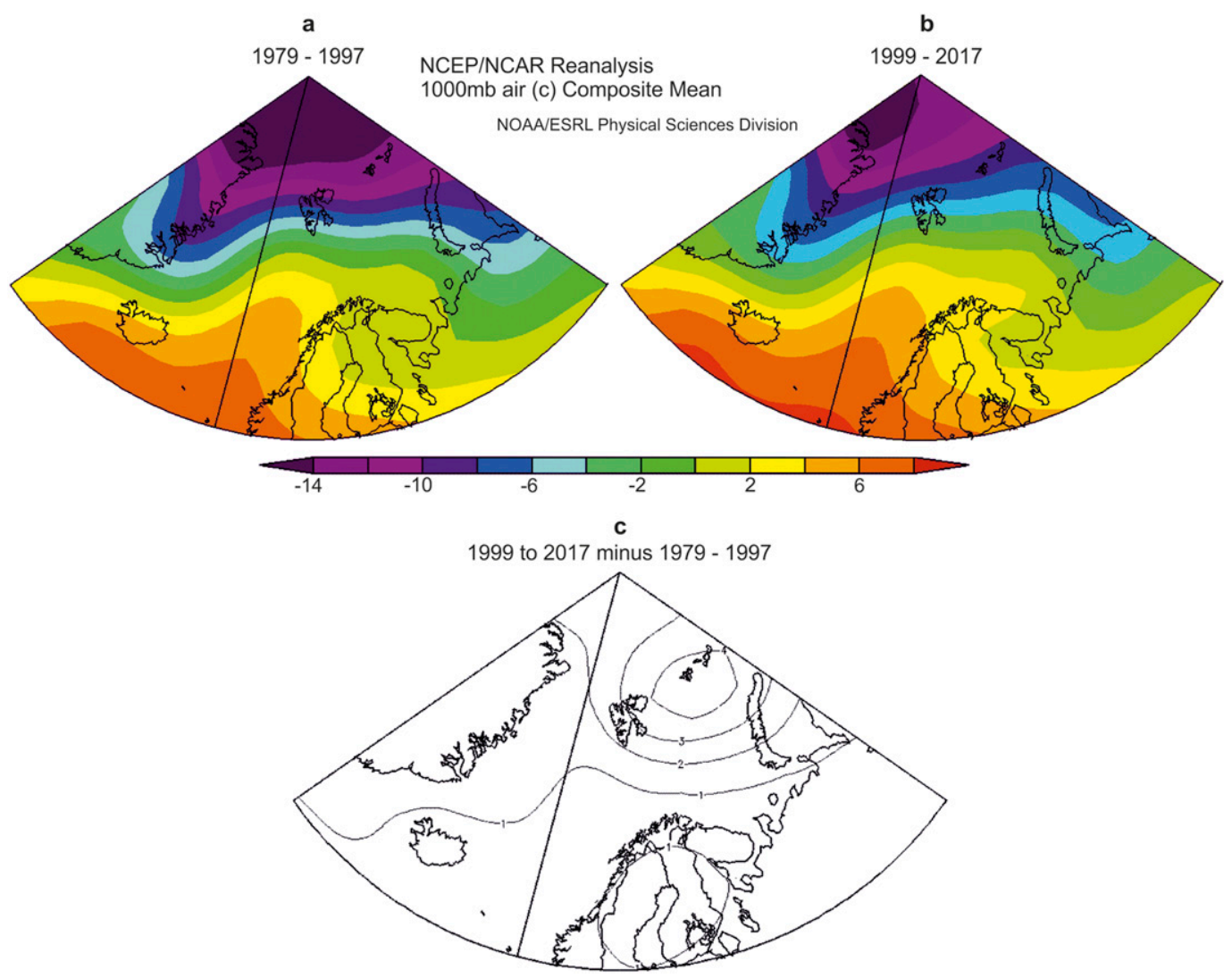

FIG. 3. Distribution of annual air temperature (based on NCEP-NCAR reanalysis) in the Atlantic sector of the Arctic in (a) 1979-97 and (b) 1999-2017, and (c) differences in air temperature between the periods. (Image provided by the NOAA/ESRL Physical Sciences Division, Boulder, Colorado, from their website at http:// www.esrl.noaa.gov/psd/.) 


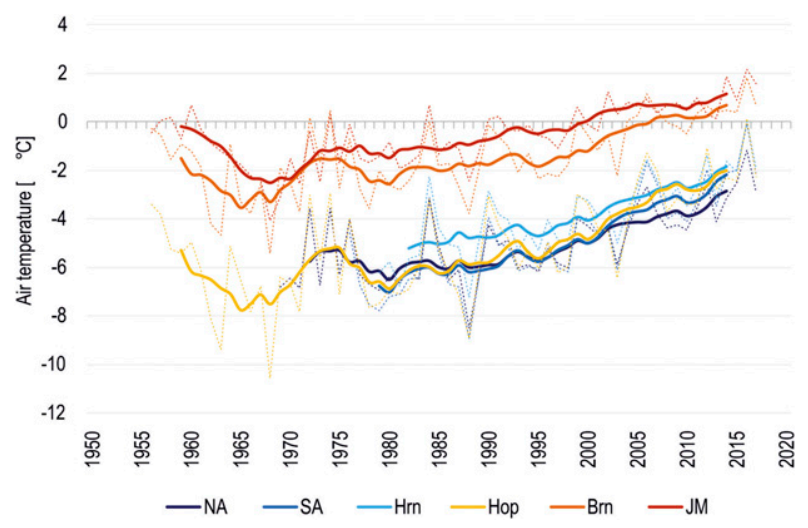

FIG. 4. Long-term course of annual air temperature in the Atlantic sector of the Arctic. There are various lengths of chronological series depending on station: NA (Ny Alesund) 1969-2017, SA (Svalbard Airport) 1976-2017, Hrn (Hornsund) 1979-2017, Hop (Hopen) 1956-2017, Brn (Bjornoya) 1956-2017, and JM (Jan Mayen) 19562017. Thin dotted lines indicate raw data and thick lines indicate moving 7-yr averages.

until the end of the series. The rate of warming was slower until the mid-1990s before accelerating in the second half of that decade (between 1995 and 1998). Thus, the first of the 19-yr periods used to assess changes in the probability of precipitation phases represents slower, insignificant warming (1979-97), whereas the second period represents accelerated, statistically significant warming (1999-2017) (Fig. 4, Table 2).

The trends calculated for the entire chronological series available for all of the stations were all statistically significant at $\alpha<0.0001$ (Table 2). Warming in the period of 1979-2017 was most rapid at NA, Hrn, and Hop, where it reached a rate of $+1.4^{\circ} \mathrm{C}$ per decade. The magnitude of the trends for most of the recent periods exceeded $1^{\circ} \mathrm{C}$ per decade, reaching a maximum of $+1.8^{\circ} \mathrm{C}$ in 1993-2017 (Table 2). Such unequivocal warming has the potential to alter the distribution of precipitation phases.

The rate of warming was unevenly distributed throughout the year. The annual course of decad air temperatures
(DAT) in the periods 1979-97 (gray lines) and 1999-2017 (red lines) and differences in DAT between these periods (gray and red bars) are presented in Figs. 5a-f. Warming was most intense between the second decad of October and the second decad of February. In this part of the year, differences in DAT reached $+4^{\circ}$ to $+6^{\circ} \mathrm{C}$ at most stations. Later decads (in 1999-2017) were all warmer compared to 1979-97; however, some decad increases were insignificant (Figs. 5a-f). Interestingly, such insignificant differences in DAT occurred at most stations between the third decad of February and the third decad of April. At JM, warming was slowest and quite evenly distributed throughout the year (Fig. 5f). Changes in the probability of precipitation phases may differ over the course of the year due to varying rates of changes in decadal air temperature.

\section{Changes in the annual probability of days with liquid, mixed, and solid precipitation}

The long-term course of annual LPP and SPP was found to respond to differing degrees and in opposite directions to changes in annual air temperature (Figs. 4, 6a-c). The probability of days with liquid precipitation, similar to the AAT, was subject to variability and short-term tendencies between 1956 and 1980, after which it increased until the end of the research period (Fig. 6a). Significant trends in the LPP were all positive and the most rapid at Brn and JM (for 1979-2017; Table 3). No significant changes were found at Hopen in this period. In the past 20 years, these trends have been accelerating, although usually not significantly. The most pronounced trends (i.e., significant in most periods) were noted in Brn, followed by those in SA (Table 3).

Changes in solid precipitation were less uniform between stations. Two patterns of long-term variability can be identified within the research area. On Spitsbergen (NA, SA, and Hrn) and at Hop, the SPP increased until the beginning of the 1990s; since then, the trend has been downward. At Brn and JM, the directions of the trends reversed approximately 10 years earlier, at the

TABLE 2. Trends (Sen's slope in ${ }^{\circ} \mathrm{C}$ per decade) in annual air temperature for long-term periods of various lengths. $\mathrm{PL}=$ period length, Var. = various length of the periods depending on station; NA = Ny Alesund, SA = Svalbard Airport, Hrn = Hornsund, Hop = Hopen, $\mathrm{Brn}=$ Bjornoya, $\mathrm{JM}=$ Jan Mayen. $\mathrm{FP}=$ full period of available data, which varies according to station as follows: NA: 1969-2017; SA: 1976-2017; Hrn: 1979-2017; Hop, Brn, and JM: 1956-2017. Statistical significance is indicated by asterisks: $*<0.05, * *<0.01, * * *<0.001$.

\begin{tabular}{|c|c|c|c|c|c|c|c|}
\hline PL & Period & NA & SA & Hrn & Hop & Brn & $\mathrm{JM}$ \\
\hline Var. & FP & $+0.8^{* * *}$ & $+1.3^{* * *}$ & $+1.1 * * *$ & $+0.8^{* * *}$ & $+0.5^{* * *}$ & $+0.5^{* * *}$ \\
\hline 19 & 1979-97 & +0.5 & $+0.8^{*}$ & +0.6 & +0.8 & +0.2 & +0.6 \\
\hline 19 & 1999-2017 & $+1.1^{* *}$ & $+1.4 * *$ & $+1.1 * *$ & $+1.4^{*}$ & $+0.8^{* *}$ & $+0.6^{*}$ \\
\hline 39 & 1979-2017 & $+1.4 * * *$ & $+1.1 * * *$ & $+1.4 * * *$ & $+1.4^{* * *}$ & $+0.9 * * *$ & $+0.8^{* * *}$ \\
\hline 30 & 1988-2017 & $+1.6 * * *$ & $+1.1 * * *$ & $+0.8 * * *$ & $+1.3 * * *$ & $+1.6 * * *$ & $+1.2 * * *$ \\
\hline 25 & 1993-2017 & $+1.4^{* * *}$ & $+1.8 * * *$ & $+1.5 * * *$ & $+1.8^{* * *}$ & $+1.3^{* * *}$ & $+0.8^{* * *}$ \\
\hline 20 & $1998-2017$ & $+1.2^{* *}$ & $+1.7 * * *$ & $+1.3^{* *}$ & $+1.6^{* *}$ & $+0.9 * * *$ & $+0.7^{*}$ \\
\hline
\end{tabular}



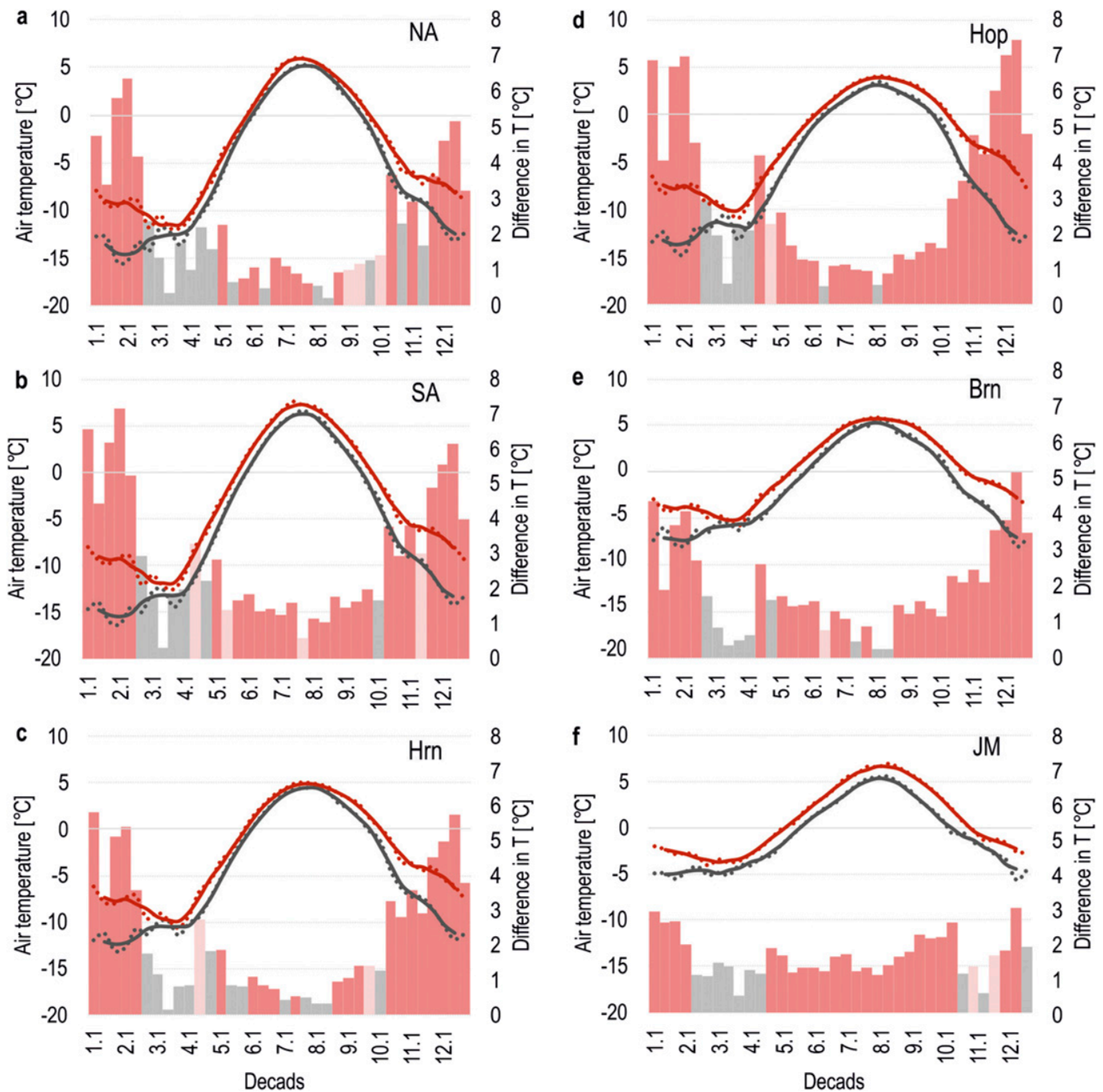

FIG. 5. Annual course of decad average air temperatures in the periods of 1979-97 (gray lines) and 1999-2017 (red lines); gray and red bars denote differences between the DAT averages; dark red bars indicate statistical significance at $\alpha \leq 0.05$ and light red bars at $\alpha<0.1$, while gray bars indicate statistically insignificant. On the horizontal axis, 1.1 indicates the first decad of January, and so on to 12.1, the first decad of December.

beginning of the 1980s. At Brn and JM, the downward trend slowed or even stopped between 2000 and 2005 (Fig. 6c). The trends in the SPP calculated for the available periods were negative at most stations but significant only at Hrn and Brn. At all stations other than NA, trends for the common period 1979-97 were significant; the strongest were those at Hop, JM, and Hrn. Over the past 20 years, both the magnitude and statistical significance of trends were weaker compared to the longer periods (Table 3 ).

Trends in the probability of days with mixed precipitation for the entire series were insignificant (Table 3) and followed various directions depending on the period and station. Indeed, for Hop and all stations located farther to the north, either short-term tendencies dominated or the long-term course of MP probability was rather stable (Fig. 6b). For shorter periods (30 to 20 years) negative trends were significant but only at Brn and JM. Since 2005, there have been clear variations in the MPP between NA and SA compared to other stations located farther to the south. Similar or even larger spatial varieties were also noticeable in the time series of SPP, which may indicate the important role of local conditions on the occurrence of precipitation phases.

\section{Changes in the decad probability of days with liquid, mixed, and solid precipitation}

The decad probabilities of days with liquid, mixed, and solid precipitation in the periods 1979-97 (gray line) 


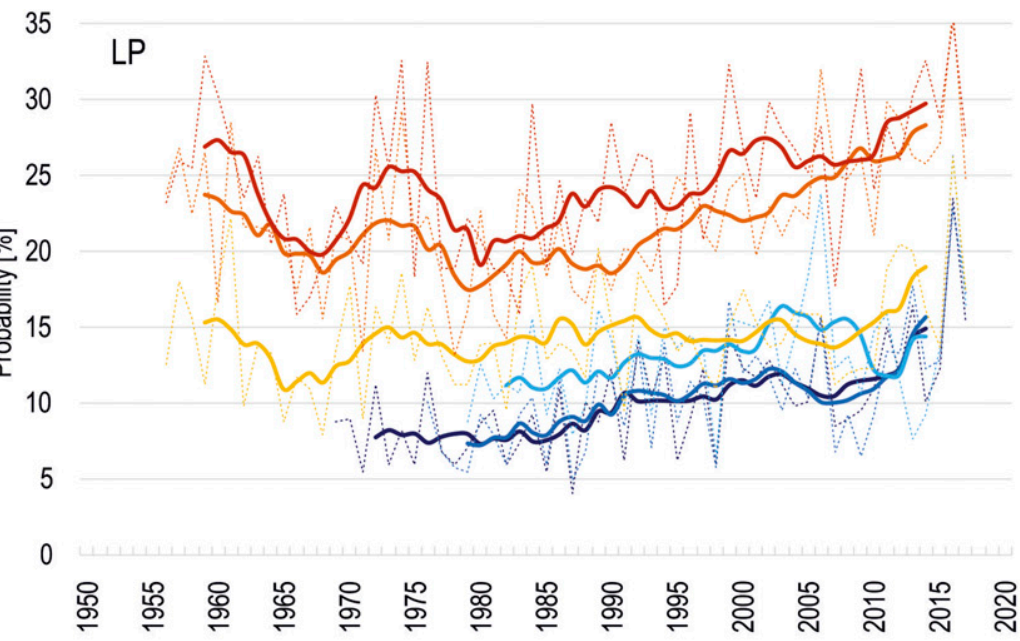

b 35
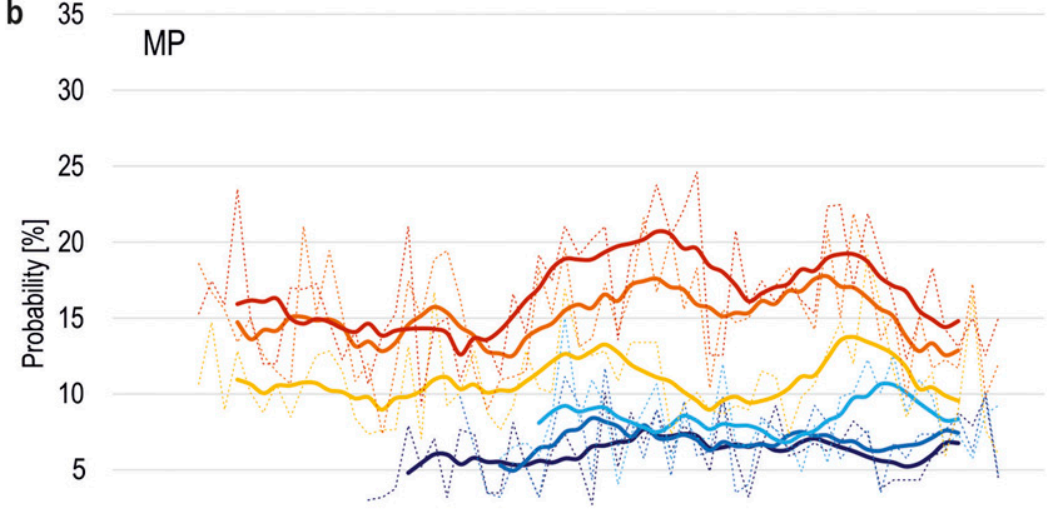

0

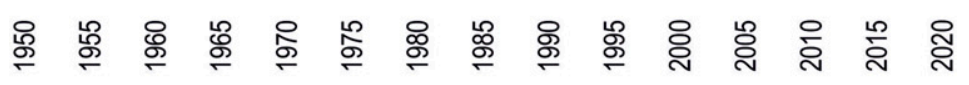

C 50



10

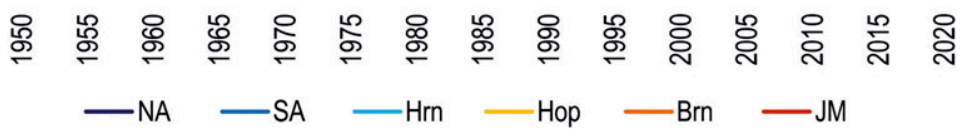

FIG. 6. Long-term course of annual probability of liquid (LP), mixed (MP), and solid (SP) precipitation in the Atlantic sector of the Arctic, for various periods depending on station: NA (Ny Alesund) 1969-2017, SA (Svalbard Airport) 1976-2017, Hrn (Hornsund) 19792017, Hop (Hopen) 1956-2017, Brn (Bjornoya) 1956-2017, and JM (Jan Mayen) 1956-2017. Thin dotted lines indicate raw data and thick lines indicate the moving 7-yr average. 
TABLE 3. Trends in annual probability (\%; Sen's slope per $10 \mathrm{yr}$ ) of liquid (LP), mixed (MP), and solid (SP) precipitation. PPh $=$ precipitation phase, $\mathrm{LP}=$ liquid precipitation, $\mathrm{MP}=$ mixed precipitation, $\mathrm{SP}=$ solid precipitation, $\mathrm{FP}=$ full period available for the station; i.e., NA: 1969-2017, SA: 1976-2017; Hrn: 1979-2017; Hop, Brn, and JM: 1956-2017. Statistical significance is shown with asterisks: $+<0.1, *<0.05, * *<0.01, * * *<0.001$. Statistically significant trends are bolded.

\begin{tabular}{|c|c|c|c|c|c|c|c|c|}
\hline $\mathrm{PPh}$ & PL & Period & NA & SA & Hrn & Hop & Brn & $\mathrm{JM}$ \\
\hline \multirow[t]{5}{*}{ LP } & & FP & $+1.4 * * *$ & $+1.7 * * *$ & $+1.0 *$ & $+0.5^{*}$ & $+0.9 * *$ & $+0.9^{*}$ \\
\hline & 39 & 1979-2017 & $+1.7 * * *$ & $+1.8 * * *$ & $+1.0 *$ & $+0.9^{+}$ & $+2.9 * * *$ & $+2.6^{* * * *}$ \\
\hline & 30 & 1988-2017 & -1.4 & $+1.4 *$ & +0.5 & +1.0 & $+3.2 * * *$ & +2.2 \\
\hline & 25 & 1993-2017 & -1.9 & $+2.0^{+}$ & +0.5 & +1.4 & $+\mathbf{3 . 0}^{* *}$ & $+3.1^{*}$ \\
\hline & 20 & 1998-2017 & +2.3 & +2.6 & -0.2 & $+2.3^{+}$ & +3.8 & -1.9 \\
\hline \multirow[t]{5}{*}{ MP } & & FP & +0.3 & +0.2 & +0.4 & 0 & 0 & +0.3 \\
\hline & 39 & 1979-2017 & +0.2 & +0.3 & +0.4 & -0.4 & -0.5 & -0.9 \\
\hline & 30 & 1988-2017 & -0.3 & 0 & +0.7 & -0.4 & $-1.8 *$ & $-1.9 *$ \\
\hline & 25 & 1993-2017 & 0 & 0 & +0.7 & +0.2 & $-1.7^{+}$ & $-2.0 *$ \\
\hline & 20 & 1998-2017 & +0.6 & 0 & +1.0 & -1.1 & $-3.1 *$ & $-1.8^{*}$ \\
\hline \multirow[t]{5}{*}{ SP } & & FP & +0.2 & -0.7 & $-2.2 * *$ & -0.4 & +0.2 & $-0.6^{+}$ \\
\hline & 39 & 1979-2017 & -0.5 & $-1.4^{+}$ & $-2.2 * *$ & $-2.4 * * *$ & $-1.6^{*}$ & $-1.9 * *$ \\
\hline & 30 & 1988-2017 & $-2.1^{* *}$ & $-3.7 * * *$ & $-3.8 * * *$ & $-3.4 * * *$ & -1.0 & $-1.4^{+}$ \\
\hline & 25 & $1993-2017$ & $-2.3^{*}$ & $-4.1 * * *$ & $-2.9 *$ & $-3.6^{* *}$ & -1.2 & -1.0 \\
\hline & 20 & 1998-2017 & $-2.7^{*}$ & $-3.9 *$ & -2.2 & -1.3 & 0 & -0.3 \\
\hline
\end{tabular}

and 1999-2017 (blue line) and differences in these 19-yr probabilities (gray bars) are shown in Figs. 7-9. The statistical significance of differences in the mean probability was tested on a monthly scale; significant cases are included in the graphs as blue transparent bars. Although every station exhibited certain individual behavior, common patterns of change are easily identifiable for every precipitation phase. The directions of significant tendencies in the SPP and LPP were usually concordant between stations, and they were related to significant changes in air temperature (although not always to the greatest changes). Minor changes or none at all occurred between the third decad of February and the third decad of April, when differences in decad air temperature between the periods were insignificant (Figs. 7-9).

Differences in decad LPP were mostly positive, indicating increases, whether significant or not, in the frequency of days with rain. The most significant and widespread of these changes occurred in the second part of the year between September and November (Fig. 7). For example, in September, the LPP increased in the latest period (1999-2017) by $10 \%-20 \%$, depending on station. On Spitsbergen, signals of increased LPP also appeared at the beginning of the warm season but not simultaneously: in April at NA and Hrn and in May at SA (Figs. 7a-c). At Brn, with relatively high winter air temperatures, a significant increase in the LPP was also found in the winter months (Fig. 7e).

Rain is a rare event in the cold part of the year; therefore, differences in the LPP calculated for decads and months between January and April should be taken with caution. In this case, statistical significance was checked but is discussed only for Brn and JM where, due to a warmer climate, rain occurred in each of the analyzed decads. Despite the low frequency and thus probability of days with LP, a noteworthy increase was found between January and April. For example, at NA, the coldest of the stations, in the early period (i.e., 1979-97) no rain events occurred in January and only 1 in February, whereas in the latest period, 1999-2017, these numbers increased to 11 and 8 , respectively. Similarly, at SA, the number of days with rainfall increased from 0 in January and 1 in February in the early period to 5 and 9 in the latter period, respectively. Increases in the frequency of LP were particularly large at Hrn, where 3 and 4 rainy days occurred in January and February, respectively, in the early period, compared to 19 and 10, respectively, in the latest period. No such spectacular changes appeared at Hop. Only at JM did the probability of liquid precipitation decrease significantly (by 10\% in July) between 1979 and 2017 due to a shift in the maximum LPP from July to August (Fig. 7f). Although insignificant, a signal of shifts in the maximum LPP was also observable at other stations (e.g., Figs. 7d,e).

Differences in the MPP were diverse with respect to both sign and location. The probability of MP declined in warm decads between July and September (Figs. 8a,d,f) and October (only Brn) (Fig. 8f), likely due to the transformation of some MP into LP. At JM and Hop, the negative differences were significant in each, or nearly each, month between June and September (Figs. 8d,f).

In the cold decads between November and January, the differences in the MPP were positive, indicating that the effect of warming on the precipitation phase in cold months was the opposite of that in warm months. Significant or weakly significant increases in some of 

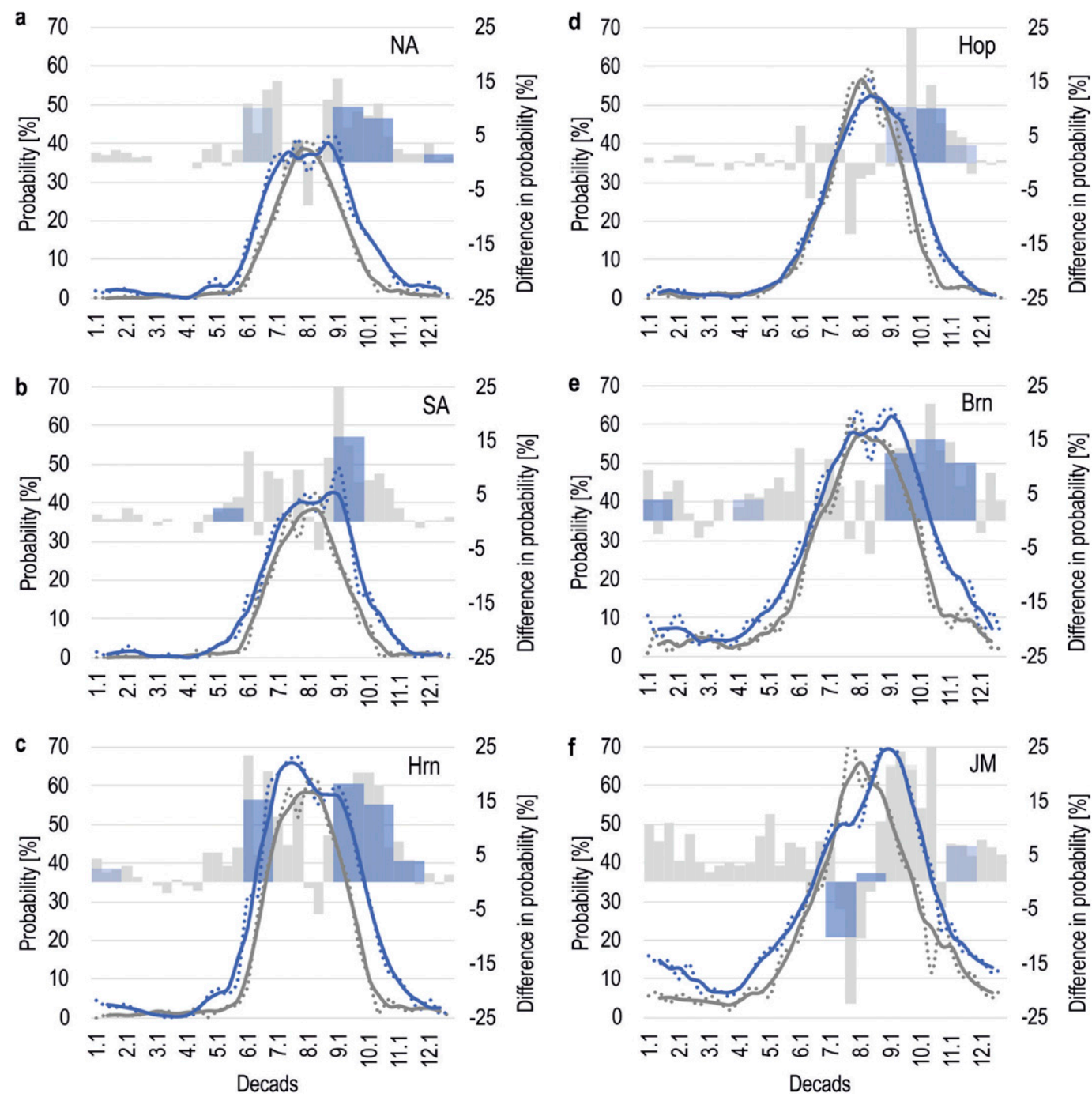

FIG. 7. Decad probability of liquid precipitation in the periods 1979-97 (gray line) and 1999-2017 (blue line) and differences in the probabilities between the periods (gray bars). Blue bars denote statistically significant differences in the monthly probability of LP (less transparent blue indicates significant at $\alpha \leq 0.05$ and more transparent blue significant at $\alpha \leq 0.1$ ). The horizontal axis indicates 1.1 (the first decad of January) and so on through 12.1 (the first decad of December).

these months were noted at almost every station, with the most prominent changes at Hop (Fig. 8d). In October, the direction of MPP tendencies varied geographically: the probability increased on Spitsbergen but decreased at lower latitudes. Minor changes in the MPP were found at SA.

All significant differences in the decad SPP were negative. Widespread changes (i.e., those occurring at almost all stations) were found in September. This decrease in the probability of snowy days was accompanied by an increase in rainy days (Figs. 7, 9). In October, despite clear increases in the LPP, a corresponding decrease in the SPP was observed only at Hop and Brn. In southern Spitsbergen and farther to the south, the SPP decreased in the winter months as well, particularly in January (Figs. 9c,e,f). This kind of signal of the impact of climate change on snowfall was most prominent at Hop, with a significant continuous decrease in the SPP from October to December and in May (Fig. 9d). Although the frequency of snowfall in the warmest months (July and August) was low, the number of days with snowfall clearly declined between the analyzed 19 -yr periods. For example, the number of days with snowfall in the period 1979-97 versus 1999-2017 was as follows: in July, Hop: 9 versus 4, Brn: 2 versus 0; in August, NA: 20 versus 8, SA: 9 versus 3, Hrn: 22 versus 4, Hop: 14 versus 7, JM: 2 versus 0 . 

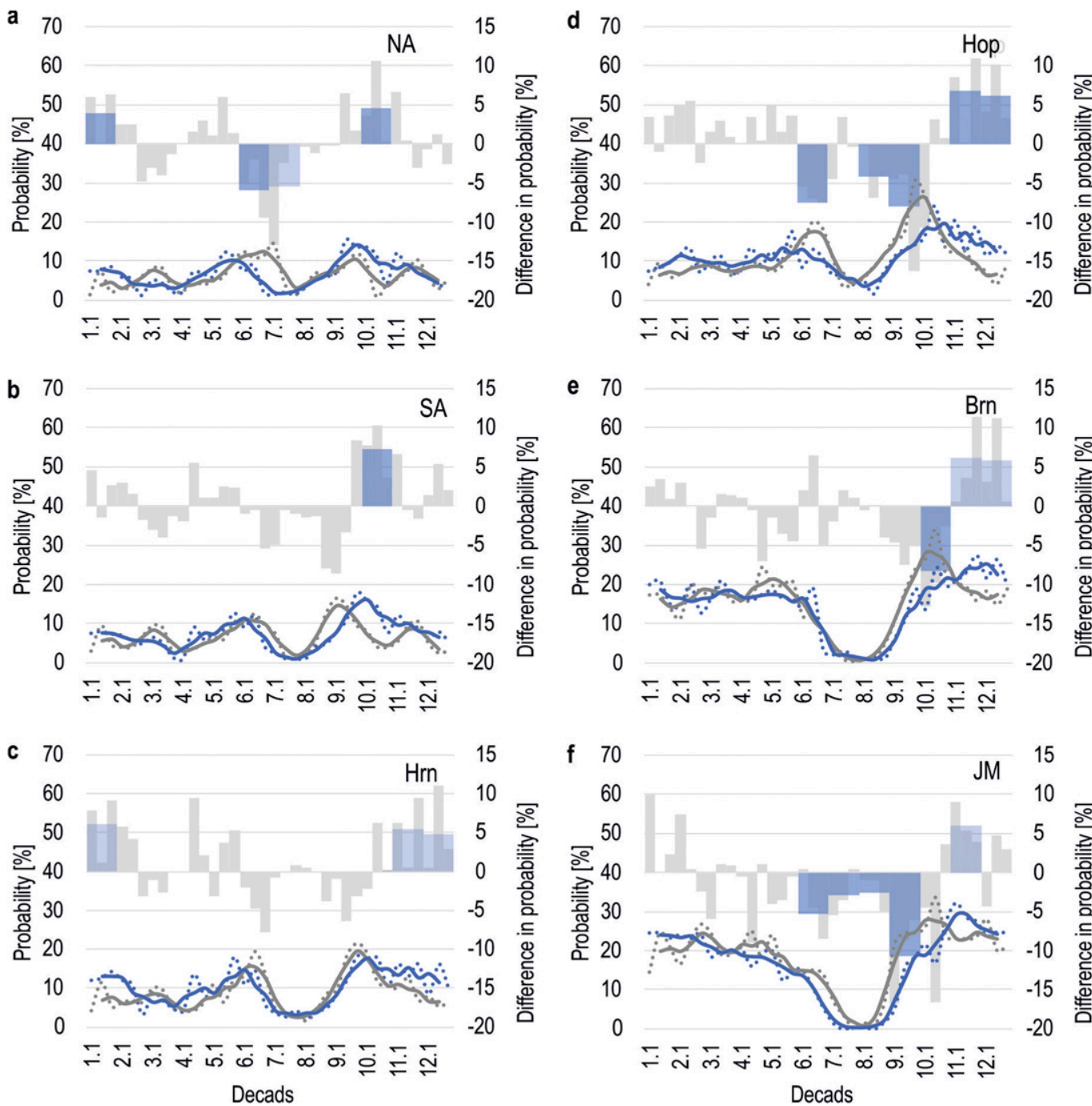

FIG. 8. Decad probability of mixed precipitation in the periods 1979-97 (gray line) and 1999-2017 (blue line) and differences in the probabilities between the periods (gray bars). Blue bars denote statistically significant differences in monthly probability of MP (less transparent blue indicates significant at $\alpha \leq 0.05$ and more transparent blue significant at $\alpha \leq 0.1$ ). The horizontal axis indicates 1.1 (first decad of January) and so on through 12.1 (first decad of December).

\section{Attribution of changes in the probability of days with snow and rain to air temperature and atmospheric circulation}

\section{a. Attribution of changes in the annual probability of precipitation phases}

Long-term variability in the probability of days with snow, rain, and mixed precipitation was correlated with air temperature, but to various degrees depending on phase and location. The correlation coefficients and coefficients of determination between the discussed variables before (Tr) and after detrending (dTr) are shown in Table 4. On an annual scale, the LPP is correlated most strongly with the AAT. The relationship between the LPP and AAT was statistically significant both before and after detrending, with the exception of NA. The strength of this relationship increased with decreasing latitude, explaining over $50 \%$ of the variability at Brn (i.e., $50 \%-56 \%$, depending on the long-term period) when variables before detrending were considered. Correlations between detrended series were lower, indicating the contributions of warming to the long-term course of the LPP. These contributions varied depending on the length of the series, but within the common period 1979-2017, they were strongest at Brn and NA, with the latter case exhibiting no significant relationship after 

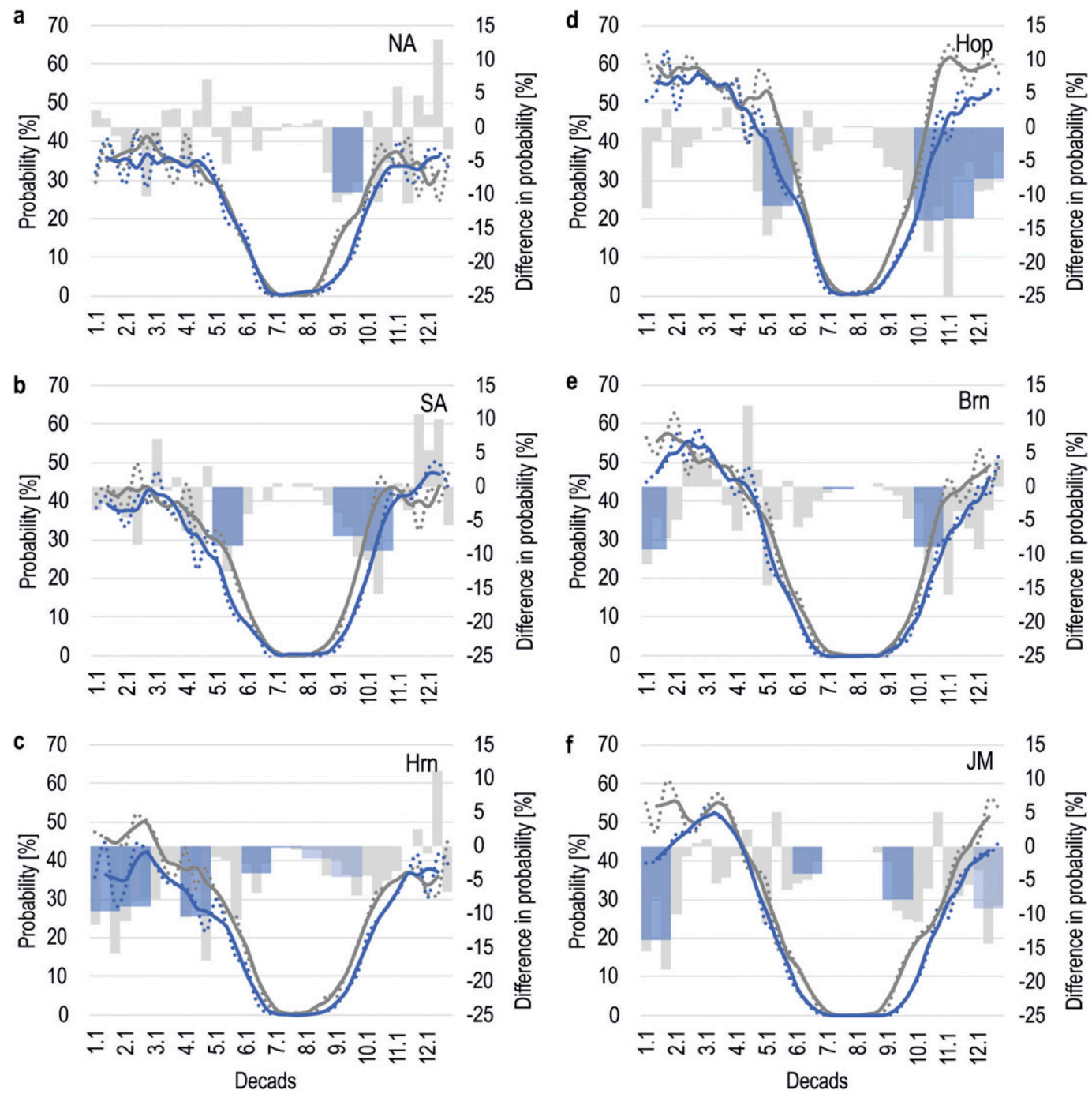

FIG. 9. Decad probability of solid precipitation in the periods 1979-97 (gray line) and 1999-2017 (blue line) and differences in the probabilities between the periods (gray bars). Blue bars denote statistically significant differences in monthly probabilities of SP (less transparent blue indicates significant at $\alpha \leq 0.05$ and more transparent blue significant at $\alpha \leq 0.1$ ). The horizontal axis indicates 1.1 (first decad of January) and so on through 12.1 (first decad of December).

detrending. In extreme cases, the trend itself increased the coefficient of determination (CD) by more than $25 \%$ (Table 4). Over the last 20 years (1998-2017), the relationships were more complicated; that is, differences in $\mathrm{CD}$ before and after detrending were smaller or bore an opposite sign compared to the longer periods. This probably resulted from generally warmer mean conditions compared to previous years and the contributions of other factors that modified the relationship between the air temperature and LPP; this area requires further indepth investigation.

Correlations between the LPP and teleconnection patterns were significant at only two stations for two different patterns (SA for NAO, Hop for PE). The weak correlation between circulation indices and the probability of days with precipitation phases on an annual scale possibly results from the prominent intra-annual variability of both variables.

Considering the longest series (the available periods and 1979-2017) (Table 4), the correlation coefficients between the AAT and MPP were significant at all stations after but not before detrending. The warming trend weakened the relationship between variables since it caused the opposite reaction of the MPP depending on the month (increase or decrease). Overlapping of these opposite reactions produced variability in the MPP unrelated to that in the AAT. Only at two southern stations (Brn and JM) was the temporal variability in annual MPP 
TABLE 4. Spearman correlation coefficient (SCC) and coefficients of determination (CD) between annual air temperature and annual probability of liquid (LP), mixed (MP), and solid (SP) precipitation before (Tr) and after (dTr) detrending. PPh = precipitation phase, $\mathrm{LP}=$ liquid precipitation, $\mathrm{MP}=$ mixed precipitation, $\mathrm{SP}=$ solid precipitation, $\mathrm{ST}=$ meteorological station, $\mathrm{NA}=\mathrm{Ny}$ Alesund, $\mathrm{SA}=$ Svalbard Airport, Hrn $=$ Hornsund, Hop $=$ Hopen, $\mathrm{Brn}=$ Bjornoya, $\mathrm{JM}=$ Jan Mayen. Statistical significance is indicated by asterisks: $*<0.05, * *<0.01, * * *<0.001$. Statistically significant correlations are bolded.

\begin{tabular}{|c|c|c|c|c|c|c|c|c|c|c|c|c|c|}
\hline \multirow[b]{3}{*}{$\mathrm{PPh}$} & \multirow[b]{3}{*}{ ST } & \multirow{3}{*}{$\begin{array}{c}\text { FP } \\
\text { Tr } \\
\text { SCC }\end{array}$} & \multirow[b]{3}{*}{$\mathrm{CD}$} & \multirow{3}{*}{$\frac{\mathrm{dTr}}{\mathrm{SCC}}$} & \multirow[b]{3}{*}{$\mathrm{CD}$} & \multicolumn{4}{|c|}{ 1979-2017 } & \multicolumn{4}{|c|}{ 1998-2017 } \\
\hline & & & & & & $\operatorname{Tr}$ & & $\mathrm{dTr}$ & & $\operatorname{Tr}$ & & $\mathrm{dTr}$ & \\
\hline & & & & & & $\mathrm{CC}$ & $\mathrm{CD}$ & $\mathrm{CC}$ & $\mathrm{CD}$ & $\mathrm{CC}$ & $\mathrm{CD}$ & $\mathrm{CC}$ & $\mathrm{CD}$ \\
\hline \multirow[t]{6}{*}{ LP } & NA & $+0.6^{* * *}$ & 38 & +0.3 & 8 & $+0.6^{* * * *}$ & 33 & +0.2 & 5 & $+0.5^{*}$ & 28 & $+0.5^{*}$ & 21 \\
\hline & SA & $+0.6 * * *$ & 41 & $+0.4 *$ & 15 & $\mathbf{+ 0 . 6 ^ { * } * * *}$ & 36 & $+0.3^{*}$ & 12 & $+0.5^{*}$ & 28 & +0.3 & 12 \\
\hline & Hrn & $+0.5^{* *}$ & 23 & $+0.4^{* *}$ & 20 & $+0.5^{* *}$ & 23 & $+0.4^{* *}$ & 20 & +0.3 & 9 & $+0.6^{*}$ & 32 \\
\hline & Hop & $+0.5^{* * *}$ & 26 & $+0.5^{* * * *}$ & 23 & $+0.4 * *$ & 18 & $+0.4^{*}$ & 13 & $+0.5^{*}$ & 23 & +0.3 & 8 \\
\hline & Brn & $+0.7 * * *$ & 50 & $+0.5^{* * * *}$ & 25 & $+0.7^{* * * *}$ & 54 & $+0.4^{* *}$ & 17 & $+0.8 * * *$ & 56 & $+0.7 * * *$ & 54 \\
\hline & $\mathrm{JM}$ & $+0.7 * * *$ & 49 & $+0.6^{* * *}$ & 36 & $+0.7^{* * *}$ & 54 & $+0.5^{* * *}$ & 29 & $+0.6^{* *}$ & 37 & $+0.7^{* *}$ & 52 \\
\hline \multirow[t]{6}{*}{ MP } & NA & $+0.4^{* *}$ & 19 & $+0.5^{* * * *}$ & 27 & +0.3 & 7 & $+0.4 * *$ & 20 & $+0.5^{*}$ & 24 & $+0.5^{*}$ & 29 \\
\hline & SA & +0.3 & 8 & $+0.4^{* *}$ & 16 & +0.2 & 6 & $+0.3^{*}$ & 12 & +0.2 & 3 & +0.3 & 7 \\
\hline & Hrn & $+0.5^{* *}$ & 21 & $+0.5^{* *}$ & 22 & $+0.5^{* * *}$ & 21 & $+0.5^{* * *}$ & 22 & $+0.5^{*}$ & 21 & +0.3 & 6 \\
\hline & Hop & +0.2 & 6 & $+0.4^{* *}$ & 15 & +0.1 & 1 & $+0.4^{*}$ & 13 & +0.1 & 1 & +0.3 & 12 \\
\hline & Brn & $+0.3^{*}$ & 10 & $+0.5^{* * * *}$ & 26 & +0.1 & 1 & $+0.4^{* *}$ & 20 & -0.2 & 3 & +0.4 & 14 \\
\hline & $\mathrm{JM}$ & +0.2 & 5 & $+0.3^{* *}$ & 12 & -0.1 & 0 & $+0.4^{*}$ & 13 & -0.3 & 7 & +0.2 & 2 \\
\hline \multirow[t]{6}{*}{ SP } & NA & +0.1 & 1 & +0.2 & 2 & -0.1 & 0 & +0.1 & 1 & -0.4 & 18 & -0.1 & 1 \\
\hline & SA & -0.1 & 1 & +0.2 & 6 & -0.2 & 3 & +0.3 & 9 & -0.4 & 15 & +0.1 & 2 \\
\hline & Hrn & -0.2 & 4 & +0.3 & 7 & -0.2 & 4 & +0.3 & 7 & +0.0 & 0 & +0.3 & 9 \\
\hline & Hop & $-0.3^{*}$ & 9 & -0.0 & 0 & $-0.5^{* *}$ & 21 & -0.0 & 0 & +0.0 & 0 & +0.1 & 0 \\
\hline & Brn & $-0.4^{* *}$ & 14 & $-0.3^{* * *}$ & 12 & $-0.5^{* *}$ & 23 & $-0.4 * *$ & 18 & -0.2 & 5 & -0.4 & 16 \\
\hline & $\mathrm{JM}$ & $-0.6^{* * *}$ & 35 & $-0.5^{* * *}$ & 26 & $-0.7 * * *$ & 45 & $-0.6 * * *$ & 37 & $-0.5^{*}$ & 30 & $-0.7^{*}$ & 42 \\
\hline
\end{tabular}

significantly related to two teleconnection patterns, including AO explaining 25\% (Brn) and 10\% (JM) and EATL/WRUS explaining 14\% (Brn) and 17\% (JM) of the variance in the MPP.

Of the probabilities, the SPP was the least sensitive to variability in air temperature, as correlations were not significant at most stations either before or after detrending. Significant relationships were found only at the stations located farthest to the south (Brn and JM). Correlations were weaker after detrending, suggesting the contribution of warming to declines in the SPP. However, this contribution was smaller than in the case of the LPP. In the common period, 1979-2017, the AAT explained as much as $23 \%(\mathrm{Brn})$ and $45 \%$ (JM) of variance in the SPP before detrending and $18 \%$ and $37 \%$, respectively, after detrending (Table 4). At the two most northern stations, temporal variability in annual LPP was under the influence of AO (NA and SA: $11 \%$ of the explained variance) and NAO (NA: $12 \%$ and SA: $22 \%$ of the explained variance).

\section{b. Attribution of changes in the monthly and decad probabilities of precipitation phases}

To determine which intervals of daily air temperature were capable of contributing to changes in the probability of days with precipitation phases, we calculated and compared the frequency of particular precipitation phases in $2^{\circ} \mathrm{C}$-wide intervals of daily air temperature between the two analyzed periods, early (1979-97) and late (1999-2017), as shown in Figs. 10a-c and 11a-c. We emphasize that the relation between the occurrence of precipitation phase and air temperature is not time dependent; thus, any changes in the frequency of precipitation phases within air temperature intervals resulted from changes in the frequency of particular air temperatures between long-term periods; these changes are presented in Figs. 10d-f and 11d-f.

At every station, we identified consecutive air temperature intervals with clearly higher or lower frequencies of precipitation types in the latest period. These intervals were separated by easily identifiable threshold values that equaled $-8^{\circ} \mathrm{C}$ at $\mathrm{NA}$ and $\mathrm{SA},-6^{\circ} \mathrm{C}$ at $\mathrm{Hrn}$, $-4^{\circ} \mathrm{C}$ at Hop, and $0^{\circ} \mathrm{C}$ at Brn and JM (Figs. 10g-1). The spatial distribution of these thresholds showed an inverse relationship with latitude.

The frequency of days with LP was greater in the latest period compared to the earlier period for air temperature intervals above $+4^{\circ} \mathrm{C}$ (SA, Hrn, Hop, JM), $+2^{\circ} \mathrm{C}$ (NA), or $+6^{\circ} \mathrm{C}(\mathrm{Brn})$ with maximum differences between $+4^{\circ}$ and $+8^{\circ},+6^{\circ}$, or $+10^{\circ} \mathrm{C}$, depending on the station. This means that the increased probability of LP was due to the greater frequency of daily air temperatures above these thresholds. Below these thresholds, the frequency of LP did not change between the two periods (Fig. 10). The 

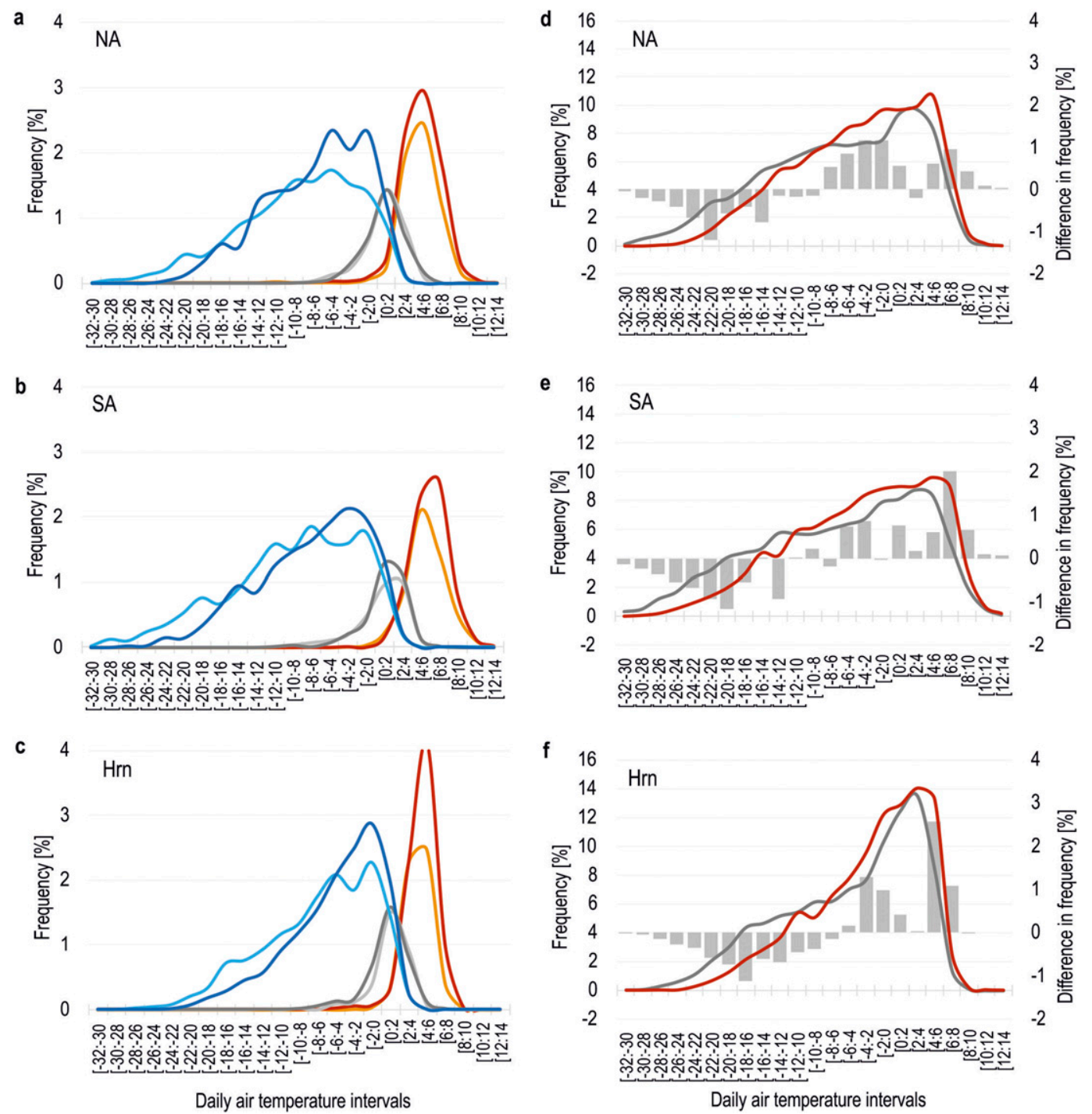

FIG. 10. (left) The frequency of liquid (LP; red lines), mixed (MP; gray lines), and solid (SP; blue lines) precipitation in daily air temperature intervals in the periods 1979-97 (light colors) and 1999-2017 (dark colors) and (right) the frequency of daily air temperatures in the periods 1979-97 (gray line) and 1999-2017 (red line) and the differences (gray bars) in the frequency of daily air temperatures between the periods in the Atlantic sector of the Arctic. NA = Ny Alesund, SA = Svalbard Airport, Hrn = Hornsund; square brackets indicate closed intervals.

threshold air temperature separating the intervals with decreased or increased frequency of days with SP was $-8^{\circ} \mathrm{C}$ (NA), $-6^{\circ} \mathrm{C}$ (SA, Hrn), $-4^{\circ} \mathrm{C}$ (Hop), $-2^{\circ} \mathrm{C}$ (Brn), and $0^{\circ} \mathrm{C}(\mathrm{JM})$. Spatial regularity in threshold air temperatures indicates the latitudinal-dependent sensitivity of solid and liquid precipitation to air temperature and its changes. Generally, changes in the frequency of days with mixed precipitation within air temperature intervals were not as clear but usually involved intervals between $-4^{\circ}$ or $-2^{\circ} \mathrm{C}$ and $+2^{\circ} \mathrm{C}$ and were most noticeable at lower latitudes (Brn, JM).

Changes in the monthly probability of days with particular precipitation phases were driven by three teleconnection patterns, SCAND, NAO, and PE. In Table 5 appear the signs of the Spearman correlation coefficients, coefficients of determination, and statistical significance of the correlations between the probabilities of days with precipitation phases and circulation indices related to the mentioned teleconnection patterns. The impact of SCAND was spatially largest between November and March and in September. This pattern positively correlated with that of the MPP, meaning that the positive phase of SCAND related to the high pressure system over the Scandinavian Peninsula increased the MPP, particularly at stations in the central and northern parts of the area. The variance in the MPP explained by SCAND varied between $12 \%$ and $34 \%$. A similar effect was 

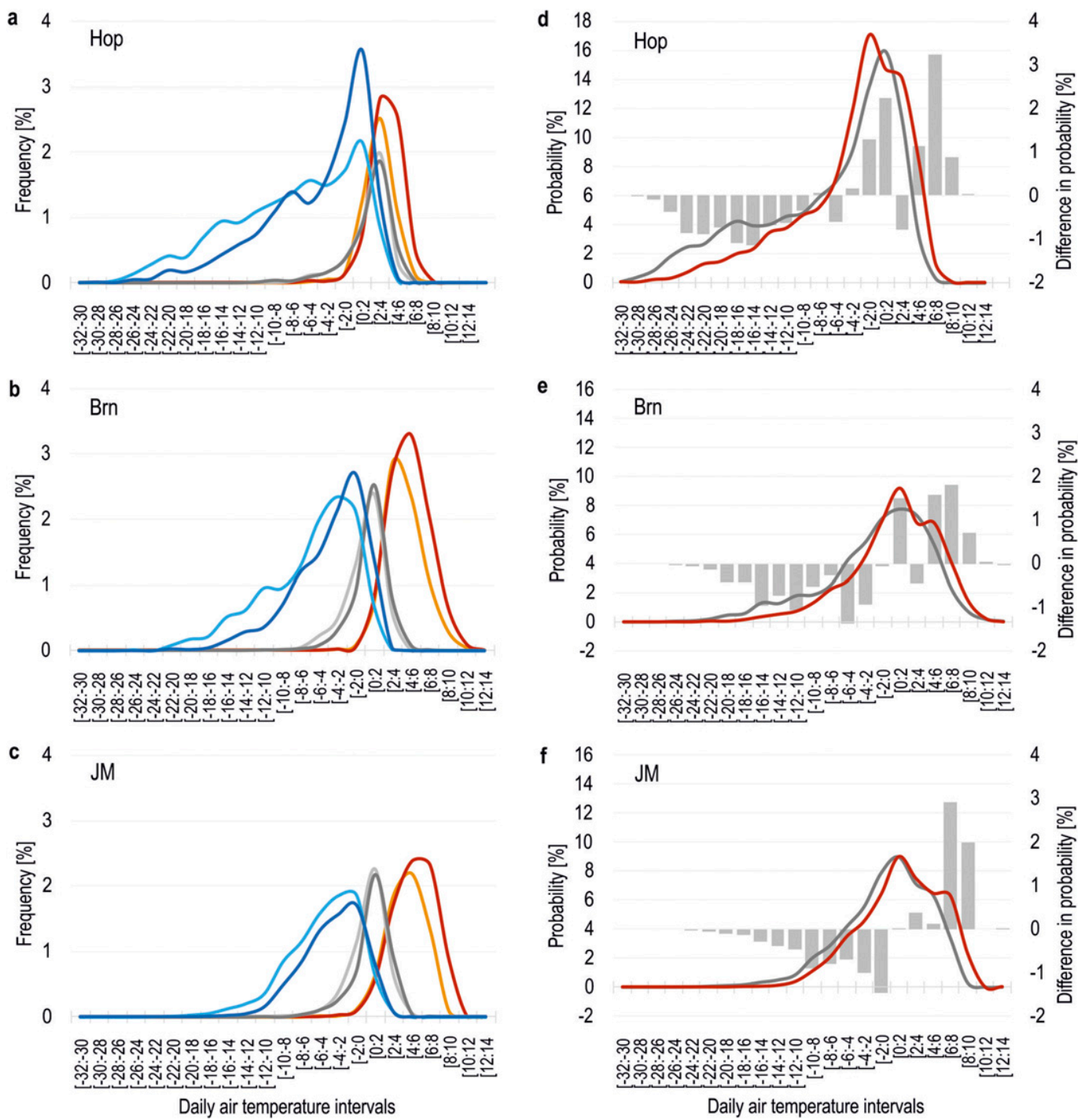

FIG. 11. (left) The frequency of liquid (LP; red lines), mixed (MP; gray lines), and solid precipitation (SP; blue lines) in daily air temperature intervals in the periods 1979-97 (light colors) and 1999-2017 (dark colors) and (right) the frequency of daily air temperatures in the periods 1979-97 (gray line) and 1999-2017 (red line) and the differences (gray bars) in the frequency of daily air temperatures between the periods in the Atlantic sector of the Arctic. Hop $=$ Hopen, Brn = Bjornoya, JM = Jan Mayen; square brackets indicate closed intervals.

found for the LPP but only in September and November (explaining $16 \%$ and $20 \%$ of the variance on average, respectively, Table 5). At JM, SCAND significantly correlated with both the LPP (positively) and the SPP (negatively) in most months (Table 5). In December and February, the effect of SCAND on the SPP transitioned northward and reached Hop.

The PE pattern related to the low pressure system over the polar region influenced temporal variability in the SPP in May, September, and October (positive correlation) and in the LPP in September and October (negative correlation) (Table 5). At southern stations (Hop, Brn, JM), the variability in the MPP was significantly driven by PE between September and November, but the sign of correlation differed depending on the month (Table 5).

The significant and widespread impact of NAO on precipitation phases was limited to April, June, and July. A NAO increase was accompanied by an increase in the LPP in June and July. The same effect was found in April for both the LPP and the MPP. The NAO most impacted the LPP at JM.

\section{Discussion}

The Atlantic sector of the Arctic is a very interesting location for a study of variability and trends in 


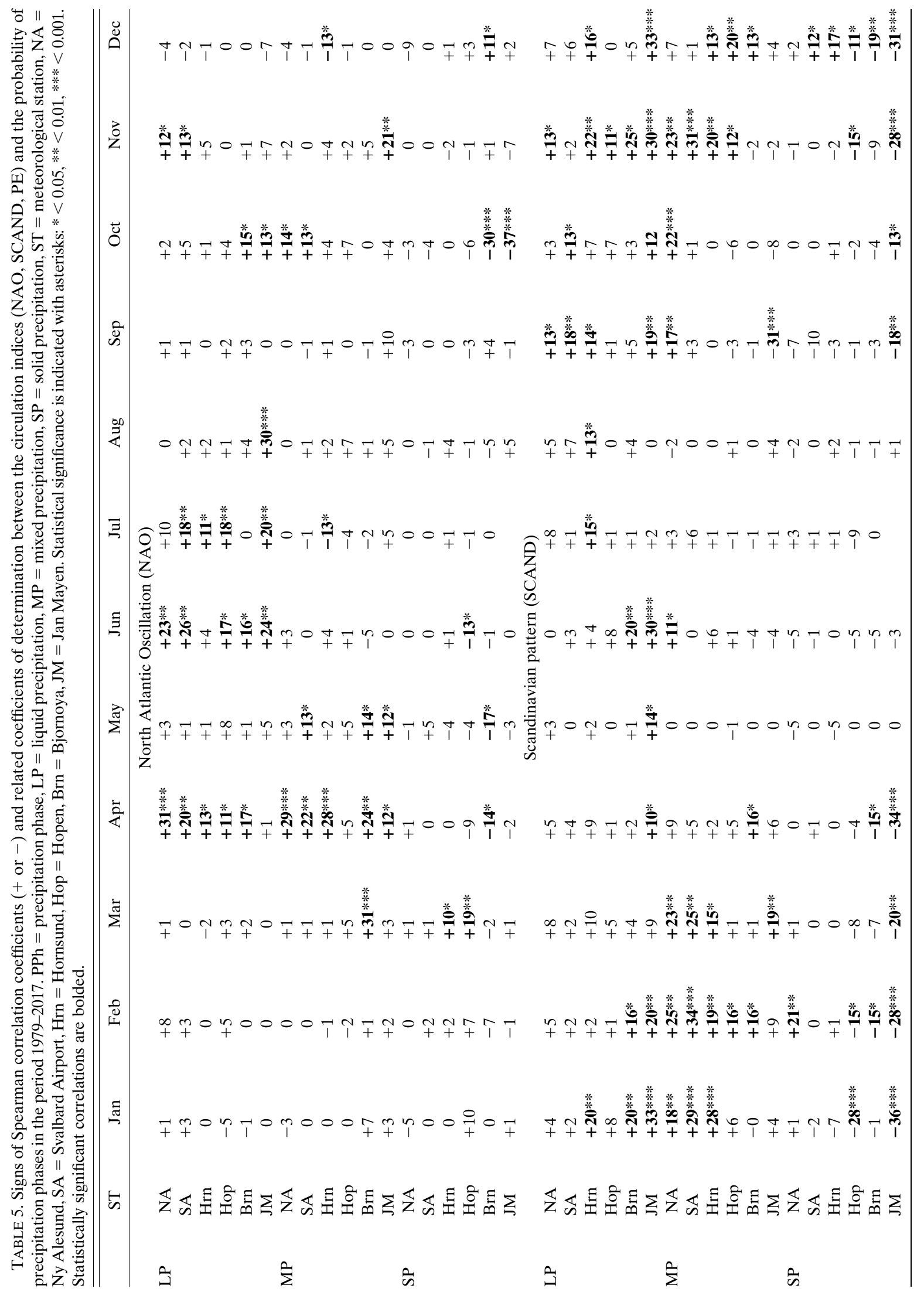




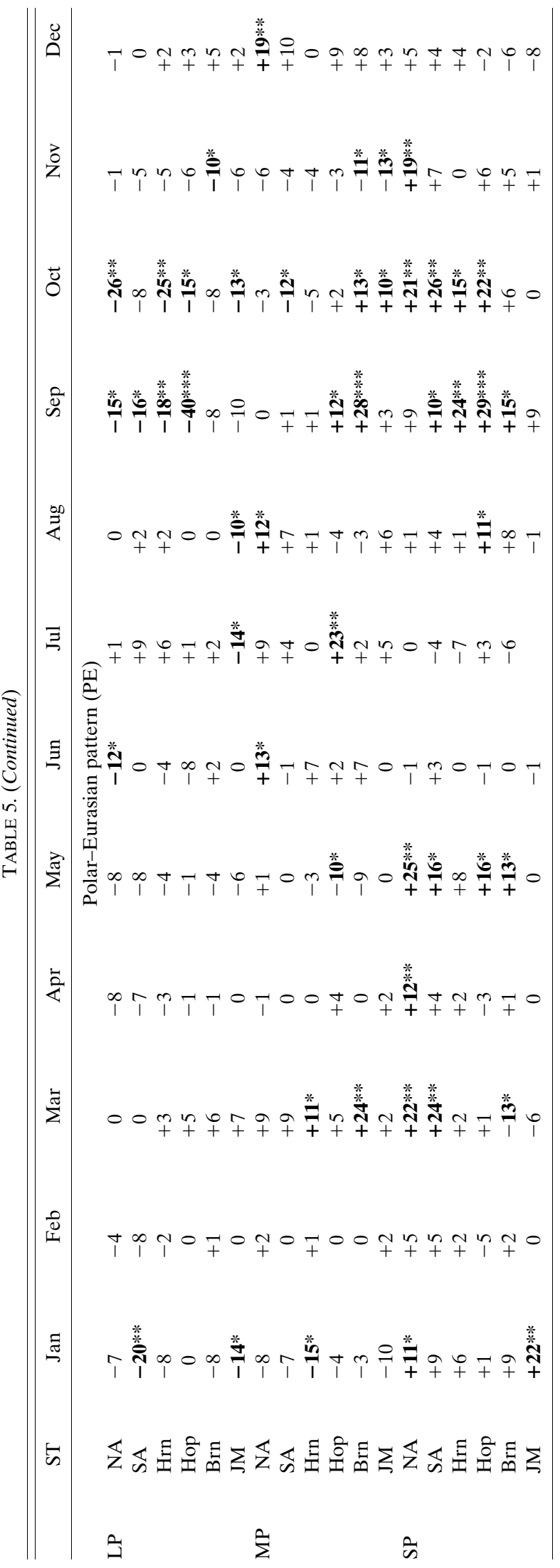

precipitation phases due to the variety of mean climates represented by particular stations, various rates of warming, and various local conditions. Increased disproportion between particular precipitation phases was found with increasing latitude and decreasing air temperature. The south-north reductions in the probability of liquid and mixed precipitation were rather regular, while the snowfall probability showed a nonlinear dependence on latitude and mean air temperature.

Arctic warming, which is proceeding at least twice as rapidly as warming on a global scale (Serreze et al. 2009; Screen and Simmonds 2010; Collins et al. 2013), has the potential to impact the frequency of days with precipitation phases. However, the relationship between these variables is not straightforward but depends on the precipitation phase and location and is additionally complicated by unevenly distributed warming within the research area of a rate varying from $>1^{\circ}$ to $>3^{\circ} \mathrm{C}$, as shown by the differences between 1979-97 and 1999-2017. Moreover, this relationship is seasonally dependent due to intra-annual variability in the rate of warming. Some decads over the course of a year showed no significant changes in air temperature between polar night and day, with the greatest extent of ice and snow cover (Parkinson et al. 1999), which may reduce the warming rate (e.g., reduced heat flux from the ocean to the atmosphere and weaker feedback mechanisms involving sea ice). In the Atlantic sector of the Arctic, the most rapid changes in the precipitation phases were not always related to the most rapid warming, either on annual and decadal scales, as temperatures remained well below the freezing point despite the warming (Knowles et al. 2006).

Liquid precipitation was found to be the phase most sensitive to air temperature. In the common period of 1979-2017, warming increased the percentage of variance in the annual LPP explained by air temperature from $16 \%$ (detrended series) to $36 \%$ (the series with trends) as averaged from all stations. Significant positive trends in the annual LPP for the common 1979-2017 period were greatest at the coldest stations. The significant reduction of sea ice on the Barents Sea (Onarheim et al. 2014) and resultant heat flux into the atmosphere (Taylor et al. 2018) may have led to a reduced probability of snowfall due to transformation into mixed precipitation rather than into rainfall, thus slowing the rate of increasing trends in the LPP. Despite local warming of the lower troposphere due to heat flux, the air temperature was still too low for the transformation of the solid phase into rainfall. A significant increase in the LPP between September and November was linked to an increased frequency of rainy days with air temperatures above geographically varying thresholds: $+2^{\circ},+4^{\circ}$, or $+6^{\circ} \mathrm{C}$, depending on the station. Spring and autumn mean air temperatures of $+6^{\circ} \mathrm{C}$ were also recognized as the 
threshold between decreasing and increasing frequency of rainfall in northern Eurasia (Ye 2008). Some increase in the LPP in this part of the year could have been driven by SCAND (positive correlation), which in its positive phase causes intensified air advection from the southwest, and the PE pattern (negative correlation), which in its negative phase weakens the polar vortex. These teleconnection patterns explained 18\% (SCAND) and $21 \%$ (PE) of the variance in the LPP.

The probability of solid precipitation decreased significantly during most of the long-term periods, indicating the persistence of SPP trends. A weak correlation between variability in the SPP and air temperature after detrending indicated that at stations with mean AATs close to or below $-4^{\circ} \mathrm{C}$, air temperature was not a dominant factor governing temporal variability in the SPP. However, Deng et al. (2017) identified daily AATs (between $1^{\circ}$ and $2^{\circ} \mathrm{C}$ in Tibet) above or below which snowfall usually decreases or increases, respectively, with increased warming. Correlations were significant at stations with mean AATs slightly below the freezing point, where warming occurred to strengthen the downward SPP trends. While uncorrelated with air temperature, significant downward trends in the SPP in colder climates suggest the contribution of local factors to the temporal course of the SPP (e.g., extent of sea ice, SST, heat flux from the ocean to the atmosphere, and/or modification of atmospheric circulation by topography); this aspect needs to be researched further. Wide spatial variation in snowfall trends despite relatively uniform changes in temperature was also reported from the Tibetan Plateau (Deng et al. 2017). The observable geographical variability of significant tendencies in monthly SPP also suggested that local factors played a role. Regional, temporal, and seasonal contrasts in snowfall trends have usually been attributed to altitude (Deng et al. 2017) and synoptic forcing (HanssenBauer and Førland 1998; Førland and Hanssen-Bauer 2003a; Deng et al. 2017).

At the coldest stations, a significant decrease in the SPP was found in transitional months (September and/or October and/or May) with air temperatures close to $0^{\circ} \mathrm{C}$. In these months, the SPP was significantly positively correlated with the EP pattern, which explained $13 \%, 20 \%$, and $21 \%$, respectively, of the variance in the SPP. A positive correlation means that a decrease in the SPP was related to a negative phase of the PE index associated with a weaker than normal polar vortex (Thompson and Wallace 1998) and enhanced exchange of air between the high and moderate latitudes. In winter, despite strong warming, air temperatures stayed far below the freezing point (Knowles et al. 2006); thus, SPP tendencies were insignificant. At stations with milder climate, negative trends in the SPP were found in
November and January or February. At these stations, due to their generally warmer climate, a lesser rate of warming was sufficient to influence snowfall even in winter. The intra-annual pattern of trends in snowfall is also location dependent; for example, in the United States, the most significant trends in solid precipitation or the solid to precipitation ratio occurred in March (Feng and $\mathrm{Hu}$ 2007). Reduced snowfall probability during the transition from autumn to winter, particularly at Hop and Hrn, may be partly related to the reduced extent of sea ice, which intensifies heat flux from the ocean into the atmosphere (Serreze et al. 2009; Screen and Simmonds 2010; Taylor et al. 2018), which in turn alters the vertical profile of air temperature and constitutes an important factor influencing precipitation phases. Higher temperatures in the troposphere affect the transformation of snowfall, thus promoting reduced snowfall frequency (Bintanja 2018). This is confirmed by an increase in the probability of rainfall, which is significant for that part of the year. Analysis of snowfall frequency as a function of daily air temperature allowed for the identification of threshold air temperatures, that is, turning points with respect to differences (negative or positive) in the frequency of snowfall. During the research period, the frequency of negative differences was higher than the frequency of positive differences, indicating that some part of the changes in snowfall may be due to the lesser frequency of air temperatures below the thresholds, rather than entirely to its transformation into the liquid phase at air temperatures close to freezing point. Winter mean air temperature of $-8^{\circ} \mathrm{C}$ was also identified as the threshold for inverse relationships between air temperature and snowfall in northern Eurasia (Ye 2008).

The probability of mixed precipitation exhibited no significant trends in 1979-2017. Significant positive trends in shorter periods for the southern part of the research area were in agreement with previous studies that identified increasing trends in the fraction of mixed precipitation in the Norwegian Arctic within the period 1975-2001 (Førland and Hanssen-Bauer 2000, 2003a,b). The insignificant correlation between air temperature and the MPP before detrending may have been caused by various responses of mixed precipitation to warming, including a reduced probability of MP between June and September due to the transformation of precipitation to liquid form and an increase in the MPP between November and January due to the transformation of snowfall into the mixed phase. Negative trends in the MPP between June and September were not driven by any of the analyzed teleconnection patterns. The positive correlation between the MPP and SCAND between November and March might have contributed to the 
increase in the MPP due to air advection from the south forced by the positive phase of the index, with prominent anticyclonic anomalies around the Scandinavian Peninsula (Bueh and Nakamura 2007).

Further research over wider areas, representing various mean climate conditions and other phase-based precipitation indices, is needed. In this study, we researched only the relationships between air temperature, macroscale atmospheric circulation, and precipitation phases. The role of local factors in shaping variability and trends in precipitation types also needs to be quantified.

\section{Conclusions}

- In the Atlantic sector of the Arctic, the probability of precipitation phases is sensitive to warming, albeit to various degrees depending on the phase, mean climate (air temperature), time of year, and local conditions.

- The probability of days with liquid precipitation (LPP) increased on an annual (from $1 \%$ to $2.9 \%$ per 10 years as shown by significant trends in 1979-2017), monthly, and decadal scales alike at all stations.

- Warming strengthened the correlation between the LPP and air temperature and may have induced increasing trends in its time series.

- Throughout the year, the LPP increased mainly in September and October, when snowfall tendencies were negative.

- Increases in the LPP were partly due to the transformation of mixed precipitation into the liquid phase and the increased frequency of warm and rainy days with daily air temperatures above the thresholds varying from $0^{\circ} \mathrm{C}$ at $\mathrm{Ny}$ Alesund to $+6^{\circ} \mathrm{C}$ at Jan Mayen.

- Temporal changes in the LPP were significantly linked to three circulation patterns, including the North Atlantic Oscillation (NAO) between April and July, the Scandinavia pattern (SCAND) in September and November, and the polar Eurasia pattern (PE) in September and November, which explained on average $19 \%, 18 \%$, and $21 \%$ of the variance with the maximum reaching $31 \%, 30 \%$, and $40 \%$, respectively.

- Trends in probability of days with solid precipitation (SPP) were negative and the most stable (i.e., significant in most analyzed long-term periods, e.g., $-1.4 \%$ to $-2.8 \%$ per decade in $1979-2017$ and approximately $-2.1 \%$ to $-4.1 \%$ per decade since 1988); however, they were also the most complicated with respect to magnitude and intra-annual pattern. The variability in the SPP was not correlated with air temperature (except at the two warmest stations), indicating that the trends were driven by factors other than air temperature. One of these factors, the PE pattern, significantly correlated with SPP in May,
September, and October and explained 13\%, 20\%, and $21 \%$ of the variance in its temporal course, respectively, and SCAND impacted the southern part of the area (Hopen, Bjornoya, Jan Mayen).

- Warming increased the correlation between the annual air temperature and SPP in the southern part of the region such that air temperature explained approximately $23 \%-45 \%$ of the variance in the SPP before detrending, compared with $18 \%-37 \%$ of the variance after detrending.

- On an intra-annual scale, negative tendencies in the SPP occurred in September, October, and May (coldest stations) or in November, January, and February (Hornsund and farther to the south).

- Negative trends in the SPP were caused partly by the transformation of snow into a mixed or liquid phase (at daily air temperatures close to $0^{\circ} \mathrm{C}$ ) and partly by the lower frequency of cold and snowy days with daily air temperatures below the thresholds varying from $-8^{\circ} \mathrm{C}$ at $\mathrm{Ny}$ Alesund to $0^{\circ} \mathrm{C}$ at Jan Mayen.

- The probability of days with mixed (MPP) precipitation exhibited no detectable annual trends due to an inverse reaction to warming in warmer (June-September) and colder (November-January) parts of the year, which cancelled out any trends. Temporal variability in the MPP on a monthly scale also depended upon SCAND between November and March and NAO in April.

Acknowledgments. This research was supported by the National Science Centre, Poland, within the framework of research project 2017/27/B/ST10/00923, "Snowfall and rain response to current climate change and atmospheric circulation in Europe." We would like to kindly thank the anonymous reviewers for their valuable comments, which enhanced the scientific quality of this paper, as well as the Polish Polar Station in Hornsund for facilitating access to the data.

\section{REFERENCES}

AMAP, 2017: Snow, Water, Ice and Permafrost in the Arctic (SWIPA). Arctic Monitoring and Assessment Programme (AMAP), 269 pp., https://www.amap.no/documents/doc/snowwater-ice-and-permafrost-in-the-arctic-swipa-2017/1610.

Andry, O., R. Bintanja, and W. Hazeleger, 2017: Time-dependent variations in the Arctic's surface albedo feedback and the link to seasonality in sea ice. J. Climate, 30, 393-410, https:// doi.org/10.1175/JCLI-D-15-0849.1.

Barnston, A. G., and R. E. Livezey, 1987: Classification, seasonality and persistence of low-frequency atmospheric circulation patterns. Mon. Wea. Rev., 115, 1083-1126, https://doi.org/ 10.1175/1520-0493(1987)115<1083:CSAPOL > 2.0.CO;2.

Bintanja, R., 2018: The impact of Arctic warming on increased rainfall. Sci. Rep., 8, 16001, https://doi.org/10.1038/s41598-01834450-3. 
Bocchieri, J. R., 1980: The objective use of upper air soundings to specify precipitation type. Mon. Wea. Rev., 108, 596-603, https://doi.org/10.1175/1520-0493(1980)108<0596:TOUOUA $>2$. $0 . \mathrm{CO} ; 2$

Bourgouin, P., 2000: A method to determine precipitation type. Wea. Forecasting, 15, 583-592, https://doi.org/10.1175/15200434(2000)015<0583:AMTDPT>2.0.CO;2.

Bueh, C., and H. Nakamura, 2007: Scandinavian pattern and its climatic impact. Quart. J. Roy. Meteor. Soc., 133, 2117-2131, https://doi.org/10.1002/qj.173.

Chapin, F. S., and Coauthors, 2005: Role of land-surface changes in Arctic summer warming. Science, 310, 657-660, https://doi.org/ 10.1126/science. 1117368 .

Cheung, Y. K., and J. H. Klotz, 1997: The Mann Whitney Wilcoxon distribution using linked lists. Stat. Sin., 7, 805-813.

Collins, M., and Coauthors, 2013: Long-term climate change: Projections, commitments and irreversibility. Climate Change 2013: The Physical Science Basis, T. F. Stocker et al., Eds., Cambridge University Press, 1029-1136.

Dai, A., 2008: Temperature and pressure dependence of the rainsnow phase transition over land and ocean. Geophys. Res. Lett., 35, L12802, https://doi.org/10.1029/2008GL033295.

— I. Y. Fung, and A. D. Del Genio, 1997: Surface observed global land precipitation variations during 1900-88. J. Climate, 10, 2943-2962, https://doi.org/10.1175/1520-0442(1997)010<2943: SOGLPV $>2.0 . C O ; 2$.

Davies, F. J., H. Renssen, and H. Goosse, 2014: The Arctic freshwater cycle during a naturally and an anthropogenically induced warm climate. Climate Dyn., 42, 2099-2112, https:// doi.org/10.1007/s00382-013-1849-y.

Davis, R. E., M. B. Lowit, P. C. Knappenberger, and D. R. Legates, 1999: A climatology of snowfall-temperature relationships in Canada. J. Geophys. Res., 104, 11 985-11 994, https://doi.org/ 10.1029/1999JD900104.

Deng, H., N. C. Pepin, and Y. Chen, 2017: Changes of snowfall under warming in the Tibetan Plateau. J. Geophys. Res. Atmos., 122, 7323-7341, https://doi.org/10.1002/2017JD026524.

Durkee, J. D., J. D. Frye, C. M. Fuhrmann, M. C. Lacke, H. G. Jeong, and T. L. Mote, 2007: Effects of the North Atlantic Oscillation on precipitation-type frequency and distribution in the eastern United States. Theor. Appl. Climatol., 94, 51-65, https://doi.org/10.1007/s00704-007-0345-x.

Feng, S., and Q. Hu, 2007: Changes in winter snowfall/precipitation ratio in the contiguous United States. J. Geophys. Res., 112, D15109, https://doi.org/10.1029/2007JD008397.

Forbes, B. C., and Coauthors, 2016: Sea ice, rain-on-snow and tundra reindeer nomadism in Arctic Russia. Biol. Lett., 12, 20160466, https://doi.org/10.1098/rsbl.2016.0466.

Førland, E. J., and I. Hanssen-Bauer, 2000: Increased precipitation in the Norwegian Arctic: True or false? Climatic Change, 46, 485-509, https://doi.org/10.1023/A:1005613304674.

— and - 2003a: Past and future climate variations in the Norwegian Arctic: Overview and novel analyses. Polar Res., 22, 113-124, https://doi.org/10.3402/polar.v22i2.6450.

$\longrightarrow$, and $\_, 2003 \mathrm{~b}$ : Climate variations and implications for precipitation types in the Norwegian Arctic. Norwegian Meteorological Institute Rep. 24/02 KLIMA, 21 pp.

- R. E. Benestad, I. Hanssen-Bauer, J. E. Haugen, and T. E. Skaugen, 2011: Temperature and precipitation development at Svalbard 1900-2100. Adv. Meteor., 2011, 893790, https:// doi.org/10.1155/2011/893790.

Gilg, O., B. Sittler, and I. Hanski, 2009: Climate change and cyclic predator-prey population dynamics in the High Arctic. Global
Change Biol., 15, 2634-2652, https://doi.org/10.1111/j.13652486.2009.01927.x.

Gjelten, H. M., and Coauthors, 2016: Air temperature variations and gradients along the coast and fjords of western Spitsbergen. Polar Res., 35, 29878, https://doi.org/10.3402/polar.v35.29878.

Grab, S., 2005: Aspects of the geomorphology, genesis and environmental significance of earth hummocks (thúfur, pounus): Miniature cryogenic mounds. Prog. Phys. Geogr., 29, 139-155, https://doi.org/10.1191/0309133305pp440ra.

Groisman, P. Ya., and D. R. Easterling, 1994: Variability and trends of total precipitation and snowfall over United States and Canada. J. Climate, 7, 184-205, https://doi.org/10.1175/ 1520-0442(1994)007<0184:VATOTP >2.0.CO;2.

— , and D. R. Legates, 1994: The accuracy of United States precipitation data. Bull. Amer. Meteor. Soc., 75, 215-228, https:// doi.org/10.1175/1520-0477(1994)075<0215:TAOUSP >2.0.CO;2.

— , V. V. Koknaeva, T. A. Belokrylova, and T. R. Karl, 1991: Overcoming biases of precipitation measurement: A history of the USSR experience. Bull. Amer. Meteor. Soc., 72 , 1725-1733, https://doi.org/10.1175/1520-0477(1991)072<1725: OBOPMA $>2.0 . \mathrm{CO} ; 2$

— E. G. Bogdanova, V. A. Alexeev, J. E. Cherry, and O. N. Bulygina, 2015: Impact of snowfall measurement deficiencies on quantification of precipitation and its trends over Northern Eurasia. Ice Snow, 126, 29-43, https://doi.org/10.15356/20766734-2014-2-29-43.

Guo, L., and L. Li, 2015: Variation of the proportion of precipitation occurring as snow in the Tian Shan mountains, China. Int J. Climatol., 35, 1379-1393, https://doi.org/10.1002/joc.4063.

Hamed, K. H., and A. R. Rao, 1998: A modified Mann-Kendall trend test for autocorrelated data. J. Hydrol., 204, 182-196, https://doi.org/10.1016/S0022-1694(97)00125-X.

Hansen, B. B., R. Aanes, I. Herfindal, J. Kohler, and B.-E. Sæther, 2011: Climate, icing, and wild Arctic reindeer: Past relationships and future prospects. Ecology, 92, 1917-1923, https:// doi.org/10.1890/11-0095.1.

_ and implications of an extreme weather event in the High Arctic. Environ. Res. Lett., 9, 114021, https://doi.org/10.1088/1748-9326/9/ 11/114021.

Hanssen-Bauer, I., and E. J. Førland, 1998: Long-term trends in precipitation and temperature in the Norwegian Arctic: Can they be explained by changes in atmospheric circulation patterns? Climate Res., 10, 143-153, https://doi.org/10.3354/ cr010143.

,-- H. Hisdal, S. Mayer, A. B. Sand $\varnothing$, and A. Sorteberg, 2019: Climate in Svalbard 2100-A knowledge base for climate adaptation. Norwegian Environment Agency, NCCS Rep. 1/2019, 105 pp., https://www.miljodirektoratet.no/globalassets/publikasjoner/ M1242/M1242.pdf.

Hu, Q., and S. Feng, 2002: Interannual rainfall variations in the North American summer monsoon region: 1900-98. J. Climate 15, 1189-1202, https://doi.org/10.1175/1520-0442(2002) $015<1189$ :IR VITN $>2.0 . \mathrm{CO} ; 2$.

Huntington, T. G., G. A. Hodgkins, B. D. Keim, and R. Dudley, 2004: Changes in the proportion of precipitation occurring as snow in New England (1949-2000). J. Climate, 17, 2626-2636, https:// doi.org/10.1175/1520-0442(2004)017<2626:CITPOP>2.0.CO;2.

Ims, R. A., and Coauthors, 2008: Collapsing population cycles. Trends Ecol. Evol., 23, 79-86, https://doi.org/10.1016/j.tree.2007.10.010.

Jakobson, E., and T. Vihma, 2010: Atmospheric moisture budget in the Arctic based on the ERA-40 reanalysis. Int. J. Climatol., 30, 2175-2194, https://doi.org/10.1002/joc.2039. 
Karl, T. R., P. Ya. Groisman, R. W. Knight, and R. R. Heim Jr., 1993: Recent variations of snow cover and snowfall in North America and their relation to precipitation and temperature variations. J. Climate, 6, 1327-1344, https://doi.org/10.1175/ 1520-0442(1993)006<1327:RVOSCA > 2.0.CO;2.

Kattsov, V. M., and J. E. Walsh, 2000: Twentieth-century trends of Arctic precipitation from observational data and a climate model simulation. J. Climate, 13, 1362-1370, https://doi.org/ 10.1175/1520-0442(2000)013<1362:TCTOAP > 2.0.CO;2.

Kausrud, K. L., and Coauthors, 2008: Linking climate change to lemming cycles. Nature, 456, 93-97, https://doi.org/10.1038/ nature 07442 .

Ke, C. Q., T. Yu, K. Yu, G. D. Tang, and L. King, 2009: Snowfall trends and variability in Qinghai, China. Theor. Appl. Climatol., 98, 251-258, https://doi.org/10.1007/s00704-009-0105-1.

Kendall, M., 1975: Multivariate Analysis. Charles Griffin \& Company, $210 \mathrm{pp}$.

Knowles, N., M. D. Dettinger, and D. R. Cayan, 2006: Trends in snowfall versus rainfall in the western United States. J. Climate, 19, 4545-4559, https://doi.org/10.1175/JCLI3850.1.

Krasting, J. P., A. J. Broccoli, K. W. Dixon, and J. R. Lanzante, 2013: Future changes in Northern Hemisphere snowfall. J. Climate, 26, 7813-7828, https://doi.org/10.1175/JCLI-D-12-00832.1.

Laternser, M., and M. Schneebeli, 2003: Long-term snow climate trends of the Swiss Alps (1931-99). Int. J. Climatol., 23, 733750, https://doi.org/10.1002/joc.912.

Legates, D. R., and C. J. Willmott, 1990: Mean seasonal and spatial variability in gauge-corrected, global precipitation. Int. J. Climatol. 10, 111-127, https://doi.org/10.1002/joc.3370100202.

Łupikasza, E., 2008: Zależność występowania rodzajów opadów od temperatury powietrza w Hornsundzie (Spitsbergen) w okresie 1978-2007 [Dependence of precipitation phases on air temperature in Hornsund (Spitsbergen) in the period 19782007]. Probl. Klimatol. Polarnej, 18, 99-112.

Mackay, J. R., 1987: Some mechanical aspects of pingo growth and failure, Western Arctic Coast, Canada. Can. J. Earth Sci., 24, 1108-1119, https://doi.org/10.1139/e87-108.

Mann, H. B., 1945: Nonparametric tests against trend. Econometrica, 13, 245-259, https://doi.org/10.2307/1907187.

Marty, C., and J. Blanchet, 2012: Long-term changes in annual maximum snow depth and snowfall in Switzerland based on extreme value statistics. Climatic Change, 111, 705-721, https:// doi.org/10.1007/s10584-011-0159-9.

Nikolova, N., P. Faško, M. Lapin, and M. Švec, 2013: Changes in snowfall/precipitation-day ratio in Slovakia and their linkages with air temperature and precipitation. Contrib. Geophys. Geodesy, 43, 141-155, https://doi.org/10.2478/congeo-20130009.

Nordli, Ø., R. Przybylak, A. E. J. Ogilvie, and K. Isaksen, 2014: Long-term temperature trends and variability on Spitsbergen: The extended Svalbard Airport temperature series 1898-2012. Polar Res., 33, 21349, https://doi.org/10.3402/polar.v33.21349.

Onarheim, I. H., L. H. Smedsrud, R. B. Ingvaldsen, and F. Nilsen, 2014: Loss of sea ice during winter north of Svalbard. Tellus, 66A, 23933, https://doi.org/10.3402/tellusa.v66.23933.

Panagiotopoulos, F., M. Shahgedanova, and D. B. Stephenson, 2002: A review of Northern Hemisphere winter-time teleconnection patterns. J. Phys. IV France, 12, 27-47, https:// doi.org/10.1051/jp4:20020450.

Parkinson, C. L., D. J. Cavalieri, P. Gloersen, H. J. Zwally, and J. C. Comiso, 1999: Arctic sea ice extents, areas, and trends, 19781996. J. Geophys. Res., 104, 20837-20 856, https://doi.org/ 10.1029/1999JC900082.
Perovich, D. K., B. Light, H. Eicken, K. F. Jones, K. Runciman, and S. V. Nghiem, 2007: Increased solar heating of the Arctic Ocean and adjacent seas, 1979-2005: Attribution and role in the ice-albedo feedback. Geophys. Res. Lett., 34, L19505, https://doi.org/10.1029/2007GL031480.

Przybylak, R., 2002: Variability of total and solid precipitation in the Canadian Arctic from 1950 to 1995. Int. J. Climatol., 22, 395-420, https://doi.org/10.1002/joc.750.

Putkonen, J., and G. Roe, 2003: Rain-on-snow events impact soil temperatures and affect ungulate survival. Geophys. Res. Lett., 30, 1188, https://doi.org/10.1029/2002GL016326.

Räisänen, J., 2016: Twenty-first century changes in snowfall climate in Northern Europe in ENSEMBLES regional climate models. Climate Dyn., 46, 339-353, https://doi.org/10.1007/ s00382-015-2587-0.

Rasmussen, R., and Coauthors, 2012: How well are we measuring snow? The NOAA/FAA/NCAR winter precipitation test bed. Bull. Amer. Meteor. Soc., 93, 811-829, https://doi.org/10.1175/ BAMS-D-11-00052.1.

Screen, J. A., and I. Simmonds, 2010: The central role of diminishing sea ice in recent Arctic temperature amplification. Nature, 464, 1334-1337, https://doi.org/10.1038/nature09051. , and 2012: Declining summer snowfall in the Arctic: Causes, impacts and feedbacks. Climate Dyn., 38, 2243-2256, https://doi.org/10.1007/s00382-011-1105-2.

Seierstad, I., D. Stephenson, and N. Kvamst $\varnothing, 2007$ : How useful are teleconnection patterns for explaining variability in extratropical storminess? Tellus, 59A, 170-181, https://doi.org/ 10.1111/j.1600-0870.2007.00226.x.

Sen, P. K., 1968: Estimates of the regression coefficient based on Kendall's tau. J. Amer. Stat. Assoc., 63, 1379-1389, https:// doi.org/10.1080/01621459.1968.10480934.

Serquet, G., C. Marty, J. P. Dulex, and M. Rebetez, 2011: Seasonal trends and temperature dependence of the snowfall/precipitation day ratio in Switzerland. Geophys. Res. Lett, 38, L07703, https:// doi.org/10.1029/2011GL046976.

Serreze, M. C., and R. Barry, 2011: Processes and impacts of Arctic amplification: A research synthesis. Global Planet. Change, 77, 85-96, https://doi.org/10.1016/j.gloplacha.2011.03.004.

_ A. P. Barrett, J. C. Stroeve, D. N. Kindig, and M. M. Holland, 2009: The emergence of surface-based Arctic amplification. Cryosphere, 3, 11-19, https://doi.org/10.5194/tc-3-11-2009.

Sevruk, B., 1993: Checking precipitation gauge performance. Measurement of Airborne Pollutants, S. Couling, Ed., ButterworthHeinemann, 89-107.

Shumway, R. H., and D. S. Stoffer, 2017: Time Series Analysis and Its Applications: With R Examples. Springer Verlag, $568 \mathrm{pp}$.

Stieglitz, M., S. J. Déry, V. E. Romanovsky, and T. E. Osterkamp, 2003: The role of snow cover in the warming of Arctic permafrost. Geophys. Res. Lett., 30, 1721, https://doi.org/10.1029/ 2003 GL017337.

Stien, A., and Coauthors, 2012: Congruent responses to weather variability in high Arctic herbivores. Biol. Lett., 8, 1002-1005, https://doi.org/10.1098/rsbl.2012.0764.

Sturm, M., C. Racine, and K. Tape, 2001: Increasing shrub abundance in the Arctic. Nature, 411, 546-547, https://doi.org/ 10.1038/35079180.

Taylor, P., B. Hegyi, R. Boeke, and L. Boisvert, 2018: On the increasing importance of air-sea exchanges in a thawing Arctic: A review. Atmosphere, 9, 41, https://doi.org/10.3390/ atmos 9020041.

Thériault, J. M., R. E. Stewart, and W. Henson, 2010: On the dependence of winter precipitation types on temperature, precipitation 
rate, and associated features. J. Appl. Meteor. Climatol., 49, 14291442, https://doi.org/10.1175/2010JAMC2321.1.

Thompson, D. W. J., and J. M. Wallace, 1998: The Arctic Oscillation signature in the wintertime geopotential height and temperature fields. Geophys. Res. Lett., 25, 1297-1300, https://doi.org/10.1029/98GL00950.

Tjernström, R., and M. G. Graversen, 2009: The vertical structure of the lower Arctic troposphere analysed from observations and the ERA-40 reanalysis. Quart. J. Roy. Meteor. Soc., 135, 431-443, https://doi.org/10.1002/qj.380.

Twardosz, R., E. Łupikasza, T. Niedźwiedź, and A. Walanus, 2012: Long-term variability of occurrence of precipitation forms in winter in Kraków, Poland. Climatic Change, 113, 623-638, https://doi.org/10.1007/s10584-011-0352-x.

Vihma, T., and Coauthors, 2016: The atmospheric role in the Arctic water cycle: A review on processes, past and future changes, and their impacts. J. Geophys. Res. Biogeosci., 121, 586-620, https://doi.org/10.1002/2015JG003132.

Walsh, J. E., V. Kattsov, D. Portis, and V. Meleshko, 1998: Arctic precipitation and evaporation: Model results and observa- tional estimates. J. Climate, 11, 72-87, https://doi.org/10.1175/ 1520-0442(1998)011<0072:APAEMR>2.0.CO;2.

Wang, J., M. Zhang, S. Wang, Z. Ren, Y. Che, F. Qiang, and D. Qu, 2016: Decrease in snowfall/rainfall ratio in the Tibetan Plateau from 1961 to 2013. J. Geogr. Sci., 26, 1277-1288, https:// doi.org/10.1007/s11442-016-1326-8.

Wilcoxon, F., 1945: Individual comparisons by ranking methods. Biom. Bull., 1, 80-81, https://doi.org/10.2307/3001968.

Yang, D., D. Kane, Z. Zhang, D. Legates, and B. Goodison, 2005: Bias-corrections of long-term (1973-2004) daily precipitation data over the northern regions. Geophys. Res. Lett., 32, L19501, https://doi.org/10.1029/2005GL024057.

Ye, H., 2008: Changes in frequency of precipitation types associated with surface air temperature over northern Eurasia during 1936-90. J. Climate, 21, 5807-5819, https://doi.org/10.1175/2008JCLI2181.1.

Zhu, X., T. Wu, R. Li, S. Wang, G. Hu, W. Wang, Y. Qin, and S. Yang, 2017: Characteristics of the ratios of snow, rain and sleet to precipitation on the Qinghai-Tibet Plateau during 1961-2014. Quat. Int., 444, 137-150, https://doi.org/10.1016/ j.quaint.2016.07.030. 